\title{
Antibiotic-loaded polypropylene surgical meshes with suitable biological behavior by plasma functionalization and polymerization
}

C. Labay ${ }^{1,2}$, J.M. Canal ${ }^{1}$, M. Modic ${ }^{3}$, U. Cvelbar ${ }^{3}$, M. Quiles ${ }^{4}$, M. Armengol ${ }^{4}$, M.A. Arbos $^{4}$, F.J.Gil ${ }^{2,5}$, C. Canal $^{2,5^{*}}$

${ }^{1}$ Surfaces, Products and Textile Processes Research Group, Textile and Paper

Engineering Dept., Technical University of Catalonia (UPC), C/ Colom, 1, 08222

Terrassa, Spain.

${ }^{2}$ Biomaterials, Biomechanics and Tissue Engineering Group, Materials Science and Metallurgy Dept., UPC, Av. Diagonal 647, 08028 Barcelona, Spain.

${ }^{3}$ Department F4, Jozef Stefan Institute, Jamova cesta 39, SI-1000 Ljubljana, Slovenia

${ }^{4}$ Grup de Recerca en Cirurgia General - VHIR, Universitat Autònoma de Barcelona, Passeig de la Vall d'Hebron, 119-129, 08035

${ }^{5}$ CIBER de Bioingeniería, Biomateriales y Nanomedicina (CIBER-BBN), Maria de Luna 11, Ed. CEEI, 50118 Zaragoza, Spain.

*Corresponding author: cristina.canal@upc.edu

\begin{abstract}
Hernia repair is one of the most common operations in general surgery, and its associated complications typically relate to infections, among others. The loading of antibiotics to surgical meshes to deliver them locally in the abdominal hernia repair site can be one way to manage infections associated with surgical implants. However, the amount of drug loaded is restricted by the low wettability of polypropylene (PP). In this work, plasma has been used to tailor the surface properties of PP meshes to obtain high loading of ampicillin while conserving the desired biological properties of the unmodified samples and conferring them with antibacterial activity. It was demonstrated that the new surface chemistry and improved wettability led to 3-fold higher antibiotic loading. Subsequently, a PEG-like dry coating was deposited from tetraglyme with low-pressure plasma which allowed maintaining the high drug loading and kept cell properties such as chemotaxis, adhesion and morphology to the same levels as the untreated ones which have shown long-standing clinical success.
\end{abstract}

Keywords: Surgical mesh, Polypropylene, Plasma, Drug delivery, Surface modification, Fibroblast. 


\section{INTRODUCTION}

In the past decade, polypropylene (PP) meshes have been used as prosthetic biomaterials not only to buttress the defect of incisional hernias, abdominal or inguinal, creating a tension-free repair [1-4] but also for the treatment of stress urinary incontinence [5], for vaginal prolapse [6] or to prevent prosthetic device infection [7]. Abdominal hernia is the protrusion of intra-abdominal content through the abdominal wall [1] from which around 1 million patients in the USA alone undergo repair surgery [8]. It has been shown that there are major physico-chemical differences between available meshes, which, in combination with the location of the mesh, the surgical technique applied and hernia type involved influence the infection potential [1]. Prosthetic device infection is a broad problem that can occur at varied stages of the materials lifespan and can be acute or delayed in their presentation [9]. The nature of device infections requires both preventive and therapeutic strategies. One of the current approaches to prevention includes the use of prophylactic preoperative systemic antibiotics. This approach should achieve adequate local tissue antimicrobial levels to fight the infection but comes at the risk of systemic effects secondary to the antibiotic exposure [7]. Several studies have shown the benefits of different kinds of antibiotics (such as cefazolin, ampicillin/sulbactam, amoxicillin or ampicillin/clavulanic acid) in the prevention of postoperative surgical site infection after inguinal PP mesh hernia repair [10-13]. However, as highlighted in the review by Bratzler et al. [10], randomized controlled trials have failed to identify an agent that is clearly superior to other agents for surgical site infection prophylaxis in hernia repair.

In recent developments, the focus has turned to improve surgical meshes incorporating cyclodextrin and maltodextrin for the prolonged release of ciprofloxacin from a PP artificial abdominal wall implant [14] or a degradable polycaprolactone/polylacide multilayer coating obtained by spraying onto PP as a carrier for the sustained release of oxofloxacin and rifampicin [15]. However, PP has low wettability and adhesion, impairing the loading of molecules directly in the polymer. Thus, Nistico et al. pretreated PP meshes with atmospheric pressure plasma dielectric barrier discharge to enhance the surface adhesion of the biopolymer chitosan which has antibacterial properties itself [16].

Plasma treatment of polymer substrates has been commonly employed to tailor surface adhesion and wetting properties by changing the surface chemical composition [17-20]. Broadly, the plasma state can be considered as a gaseous mixture of a number of active species, including oppositely-charged particles that preserve electrical charge neutrality [21]. Appropriate selection of the plasma source enables the introduction of diverse functional groups on the target surface to improve wettability, biocompatibility or to allow subsequent covalent immobilization or physical adsorption of various molecules 
such as dyestuffs [22], pharmaceutical or cosmetic active principles [23-24]. Plasma can also be used for the deposition of thin polymer films by the so-called plasma polymerization process. Coating by plasma polymerization is defined as the formation of thin polymer coatings, on a surface such as a polymeric biomaterial, under the influence of plasma conditions $[25,26]$. By modifying the process parameters and the precursor molecule, different kinds of biocompatible coatings can be produced, from cell-adhesive coatings to antifouling coatings.

The aim of the present work is to obtain antibiotic-loaded PP meshes with enhanced drug loading on the materials while preserving their biological behavior using a novel approach by combining different plasma processes. Thus, plasma surface functionalization of PP meshes is investigated to increase the potential amount of ampicillin loading. As the expected wettability enhancement produced by plasma may modify the biological behavior of the material, low pressure plasma polymerization with a PEG-like precursor was examined to obtain a thin layer of polymer on the surface through a dry method. To understand better the processes, the physicochemical material properties were studied at different stages of treatment along with material performance of drug release, antibacterial activity and cell adhesion.

\section{EXPERIMENTAL PART}

\section{Materials}

A polypropylene surgical knitted mesh, made from a $0.15 \mathrm{~mm}$ diameter monofilament, with $1.3 \times 1.0 \mathrm{~mm}$ pore size and $97.0 \pm 2.0 \mathrm{~g} / \mathrm{m}^{2}$ weight, (SurgicalMesh ${ }^{T M}$, USA) was selected for this research. For contact angle measurements a PP film (Goodfellow) was used as a model surface. To avoid the potential influence of the additives used during polypropylene manufacture on the wetting properties of the materials, we prepared the surface of both materials by washing following the same protocol [24].

Ampicillin sodium salt $(371.39 \mathrm{~g} / \mathrm{mol})$, provided by Sigma Aldrich ${ }^{\circledR}$ was selected for incorporation in the PP mesh, and presents a water solubility of $50 \mathrm{mg} / \mathrm{mL}$.

Tetraetylene glycol dimethyl ether (tetraglyme, Sigma Aldrich) $\mathrm{CH}_{3} \mathrm{O}\left(\mathrm{CH}_{2} \mathrm{CH}_{2} \mathrm{O}\right)_{4} \mathrm{CH}_{3}$ ) was used as precursor for plasma polymerization. Phosphate buffer saline (PBS), pH 7.4, was prepared from $\mathrm{KH}_{2} \mathrm{PO}_{4}$ (Fagron Iberica S.A.V, Spain), $\mathrm{Na}_{2} \mathrm{HPO}_{4}$ (Probus S.A, Spain), $\mathrm{NaCl}$ (Acofarma ${ }^{\circledR}$, Spain), and Milli-Q ${ }^{\circledR}$ deionized water. All chemicals used were of analytical grade. Orthophosphoric acid $\left(\mathrm{H}_{3} \mathrm{PO}_{4}\right), 85 \%$ purity, from Scharlab S.L. (Spain) was used to adjust the $\mathrm{pH}$ value of the phosphate buffer solution.

Agar bacteriological (Scharlau S.A., Spain) and Brain Heart Infusion Broth (BHI Broth) (Scharlau S.A., 02-599, Spain) were used to prepare the bacteriological culture media of Staphilococcus aureus and Escherichia coli. 


\section{Plasma surface functionalization}

Plasma functionalization treatments (F-) at atmospheric pressure were carried out by means of an Ahlbrandt FG-2 (Germany) corona plasma using air as the plasma forming gas. The distance between the electrode and the fabric was adjusted to $10 \mathrm{~mm}$. During the treatments, power, speed and discharge current were kept constant at $380 \mathrm{~W}, 15$ r.p.m. and 1.90 A respectively. Fabrics were treated for $1.05 \mathrm{~s}, 1.75 \mathrm{~s}, 3.5 \mathrm{~s}$ and $7.0 \mathrm{~s}$ (samples are coded as F-1.05s, F-1.75s, F-3.5s, F-7s) (Fig. 1).

To minimize the ageing process of all plasma-treated samples [27-29], analysis and post-treatments (including fabric loading) were carried out immediately following plasma treatment of the fabrics.

\section{Plasma polymerization coatings}

Plasma polymerization of polyethylene glycol (PEG) was carried out with low-pressure radio-frequency plasma $(13.56 \mathrm{MHz})$ (Standard Femto Plasma System, Diener, Germany), by introducing tetraglyme in the plasma chamber by bubbling a carrier gas (argon) through liquid tetraglyme. Polymerization treatment was performed at $0.4 \mathrm{mbar}$ for 2 hours at an average power of $200 \mathrm{~W}$; the plasma was pulsed with a pulse width of $20 \mu$ s with $20 \mathrm{~ms}$ between pulses. Before polymerization, a short surface activation step was carried out with argon, at 0.40 mbar of pressure for $30 \mathrm{~s}$ at $100 \mathrm{~W}$.

\section{Antibiotic loading of PP meshes}

Polypropylene meshes were cut into rectangular samples of $(7.0 \times 5.0) \mathrm{cm}$, weighing approximately $0.32 \mathrm{~g}$ each. Loading of the PP samples was carried out by immersion in a $4 \%$ ampicillin solution in distilled water at a fabric/bath relation of 1/10, during $24 \mathrm{~h}$ with continuous shaking at 160 r.p.m. at $20{ }^{\circ}$ C. Subsequently, PP samples were submitted to a double padding process under $1 \mathrm{~kg} / \mathrm{cm}^{2}$ pneumatic pressure and $1 \mathrm{~m} / \mathrm{min}$ speed working conditions. Samples were finally dried in an oven during 24 hours at 37 ${ }^{\circ} \mathrm{C}$. The samples were weighed before and after the loading process to calculate the amount of caffeine in the fibres and the loading ratio. A minimum of 4 replicates were done for each kind of sample.

\section{In vitro release assays}

Drug release assays were adapted from the USP dissolution test [30]. Five thermo-

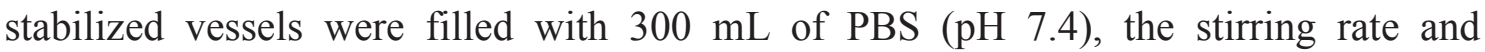
temperature were maintained at 25 r.p.m. and $37{ }^{\circ} \mathrm{C}$ respectively, during the 4 hours of the release experiment. The PP meshes were placed on a vertical stainless steel holder 
that ensures optimum contact between the textile materials and the buffer solution. 1 $\mathrm{mL}$ samples were withdrawn from the receptor compartment for latter spectroscopy analysis [23]. After each sample withdrawal, the same volume of fresh PBS was added to the receptor medium. Sink conditions were kept constant in the receptor solution during the experiment [31]. 4 replicates of antibiotic-loaded PP with the different treatments were studied, together with an un-loaded mesh used as a reference.

\section{Surface topography analysis}

Topography of the untreated and plasma treated PP meshes was studied by FieldEmission Scanning Electron Microscopy using a Jeol JSM 5000 SEM. All samples were Au coated prior to SEM observation. Observations were carried out at $15 \mathrm{kV}$ working voltage.

Atomic Force Microscopy (AFM) was performed with a Solver PRO 47 (NT-MDT, Moscow, Russia). Oscillating semicontact mode with Si cantilever (NSG 10 from NTMDT, Moscow, Russia) with a typical force constant of $11.8 \mathrm{Nm}^{-1}$, operating at a typical resonance frequency of $240 \mathrm{kHz}$ was used for surface imaging over range $1 \times 1$ to $20 \times 20 \mu \mathrm{m}^{2}$. Surface roughness $R_{a}$ was calculated as the mean of the average surface roughness after subtraction of the background from the image.

\section{Static contact angle}

A Krüss DSA100 goniometer was used for the acquisition of the measures. Due to the difficulty of measuring contact angle on the fibres, a PP film was used as a model surface. Untreated (UT) and plasma-treated PP films were laid flat on a glass support and $10 \mu \mathrm{L}$ water droplets were deposited on the film. Measurements were carried out on the plasma-treated side of the samples. In this study, 5 replicates of each measurement were carried out.

\section{X-Ray Photoelectron Spectroscopy (XPS)}

X-ray Photoelectron Spectroscopy analysis of the PP meshes was performed in a XPS Spectrophotometer TFA XPS (Physical Electronics Inc., Chanhassen, Minnesota, USA). An Al monochromatic source of X-ray light with a power of $250 \mathrm{~W}$ was used. The relative error for XPS determination is about $0.5 \%$. Each sample was analyzed at two different places and the average composition was calculated. In addition to the wide energy range spectra, high-energy resolution spectra of characteristic peaks of $\mathrm{C}_{1 \mathrm{~s}}, \mathrm{O}_{1 \mathrm{~s}}$, $\mathrm{N}_{1 \mathrm{~s}}$ and $\mathrm{Si}_{2 \mathrm{p}}$ elements are recorded through a narrow energy range. Spectra were referenced to the $\mathrm{C}_{1 \mathrm{~s}}$ peak, at $284.80 \mathrm{eV}$ [32]. 


\section{Cell cultures}

\subsection{Cell lines}

Cell lines used in this study were purchased from the American Tissue Type Culture Collection (ATCC) [33]. Studies were performed using two mammalian cell lines (purchased from ATCC/LGC Standards, Spain); human monocyte THP-1 (TIB-202), and mouse fibroblast NIH/3T3 (CRL-1658). THP-1 monocytes were grown in RPMI medium 1640 (Gibco/Life-Technologies, Spain), supplemented with 10\% FBS (Thermo Fisher Scientific, Spain), $100 \mathrm{U} / \mathrm{ml}$ penicillin, $100 \mu \mathrm{g} / \mathrm{ml}$ streptomycin sulfate, and 2 mM L-glutamine (Gibco/Life-Technologies, Spain). NIH/3T3 fibroblasts were propagated in Dulbecco's Modified Eagle Medium (DMEM; Gibco/Life-Technologies, Spain) with $2 \mathrm{mM}$ L-glutamine supplemented with 10\% fetal bovine serum (FBS), 100 $\mathrm{U} / \mathrm{ml}$ penicillin $\mathrm{G}$ and $100 \mu \mathrm{g} / \mathrm{ml}$ streptomycin. Cells were maintained at $37{ }^{\circ} \mathrm{C}$ in a humidified atmosphere of $5 \% \mathrm{CO}_{2}$.

\subsection{Preparation of conditioned media}

Sterile-packaged meshes (gamma sterilized at $8 \mathrm{kGy}$ ) were always processed under a sterile laminar flow hood. Upon receipt, the material was cut and rinsed in 0.1 M PBS, $\mathrm{pH}$ 7.4. The resulting fragments were added to a complete cell growth medium without antibiotic $\left(2 \mathrm{~cm}^{2} \mathrm{mesh} / \mathrm{mL}\right.$ medium $)$ containing $2 \%$ or $10 \%$ FBS depending on the assay used, and placed in an incubator for the specified time at $37{ }^{\circ} \mathrm{C}, 5 \% \mathrm{CO}_{2}$. Afterwards, the conditioning PP material was removed and the media was collected and passed through a $0.20 \mu \mathrm{m}$ filter unit (Millipore). Additional control medium was processed simultaneously.

\subsection{Proliferation and viability assays}

Cell viability behavior of the meshes was evaluated using conditioned media-treated THP-1 human monocytes and NIH-3T3 mouse embryonic fibroblast cells. THP-1 cells were plated at an initial density of $1 \times 10^{5}$ cells $/ \mathrm{ml}$ in 24 -well dishes $(0.5 \mathrm{~mL} /$ well $)$ in mesh-conditioned medium. At 24, 48 and $72 \mathrm{~h}$ after plating, cell density was determined using a cell counter (Z $\mathrm{Z}^{\mathrm{TM}}$ Series Coulter Counter ${ }^{\circledR}$, Beckman Coulter, Barcelona, Spain). The percent growth was calculated according the following equation:

$$
\% \text { cell growth }=((\text { final cell density }- \text { initial cell density }) / \text { initial cell density }) \times 100
$$

Trypan blue dye exclusion staining was also performed to assess cell viability.

A suspension of $\mathrm{NIH} / 3 \mathrm{~T} 3$ cells was used to seed $1 \times 10^{4}$ cells in $0.5 \mathrm{~mL}$ of complete medium (w/o antibiotics) /chamber in 24-well dishes. After overnight incubation under standard conditions, the culture supernatants were aspirated, and each well was rinsed with $0.1 \mathrm{M}$ PBS before being supplied with $0.5 \mathrm{~mL}$ of mesh-conditioned medium. After 
incubation for 24 and 48 hours, cells were gently washed with $0.1 \mathrm{M}$ PBS $(\times 3)$. Cells remaining on the bottom surface were fixed (ice-cold 100\% methanol, $10 \mathrm{~min}$ ) and stained $(0.5 \%$ crystal violet solution in $25 \%$ methanol, $\mathrm{w} / \mathrm{v}, 15 \mathrm{~min})$. The plate was gently washed and once dried, cells were observed under an inverted bright-field microscope. After that, crystal violet was dissolved in 1\% SDS solution and analyzed by spectrophotometry (OD $590 \mathrm{~nm}$ ).

\subsection{Chemotaxis assay}

The chemotactic migration response to conditioned media was assessed in NIH/3T3 fibroblasts using $6.5 \mathrm{~mm}$ Transwell@ migration devices $(8 \mu \mathrm{m}$-pore polycarbonate membrane, Corning, Lowell, MA, USA) following supplied instructions. Cells $\left(1 \times 10^{5}\right.$ cell $/ \mathrm{ml}$ ) were plated in DMEM supplemented with $2 \%$ FBS $(\mathrm{v} / \mathrm{v})$ into the upper chamber and incubated at $37{ }^{\circ} \mathrm{C}, 5 \% \mathrm{CO}_{2}$. The lower chamber was filled with conditioned and control media (both using DMEM with either $2 \%$ or $10 \%(\mathrm{v} / \mathrm{v})$ FBS). Twenty-four hours later, non-migrated cells were scraped off of the filter's upper surface. The insert was removed and stained with crystal violet as explained above to quantify cells migrating through the filter and remaining attached to its lower side for each well. Chemotactic index was calculated as the ratio of cell migration toward conditioned media divided by cell migration toward media alone.

\subsection{Cell adhesion}

Cell attachment on each substrate was evaluated by recording the number of NIH/3T3 fibroblasts attached after $24 \mathrm{~h}$ of incubation. Meshes were fixed in 12-well dishes using CellCrownTM inserts (Scaffdex, Sigma-Aldrich, Madrid, Spain) over a non-adhesive agarose layer $(0.9 \%)$ polymerized in the bottom of each well. A number of $1 \times 10^{5}$ cells/well were seeded onto the materials. After incubation, the specimens were washed with D-PBS $(3 \times)$ to eliminate unattached cells and the adherent cells were stained with crystal violet and photographed using bright-field microcopy. The results were expressed as the number of adherent cells per unit surface of the material (counts in 10 fields per condition).

\section{Antibacterial assays}

The antibacterial activity of the treated meshes was tested against Staphylococcus aureus (S. aureus) CCUG 15915 and Escherichia coli (E. Coli) CCUG 10979 and (Culture Collection University of Göteborg (CCUG), Göteborg, Sweden). To qualitatively determine the antibacterial activity on the treated textile materials the Parallel Streak Method AATCC Test Method 147-2004 was used. This method consists of placing several parallel streaks in a standard Petri dish with the appropriate culture media for the bacteria tested, in this case Brain Heart Infusion Broth (BHI Broth) (Scharlau S.A., 02-599, $500 \mathrm{~g}$, lot 10227) at $[\mathrm{BHI}]=37.0 \mathrm{~g} \cdot \mathrm{L}^{-1}$. 


\section{RESULTS}

3.1. Influence of plasma treatment on the surface chemistry of the PP mesh

The behavior of the static water contact angle on the untreated (UT) and plasma functionalized (F) PP film - used as a model surface for the PP fibres - is shown in Fig. 2. It can be observed that the UT PP film, with a contact angle of $124.4^{\circ}$, has a clear hydrophobic character. Whereas when it is treated with air plasma, under any of the experimental conditions tested, it acquires hydrophilic properties, showing contact angles below $90^{\circ}$. It can be observed that contact angle shows an exponential decrease as a function of $\mathrm{F}$ plasma treatment time and thus wettability is significantly improved in all cases. A plateau is reached at approximately $25^{\circ}$ after $3.5 \mathrm{~s}$ of treatment.

It can also be observed that the plasma polymerization treatment of Tetraglyme using argon as carrier gas to create PolyEthyleneGlycol coatings (PEG) additionally modifies the wettability of PP. After the plasma polymerization treatment, the wettability of UT PP dropped significantly (46.5\%). The same treatment on the F-3.5s+PEG plasma treated sample led to superhydrophilic properties, with contact angle of $0{ }^{\circ}$.

Table 1 details the elemental relative composition of the fibre surface of UT, F-plasma and PEG plasma coated PP meshes. The untreated PP mesh presents a surface composition with $84 \%$ of $\mathrm{C}_{1 \mathrm{~s}}$ and $10 \%$ of $\mathrm{O}_{1 \mathrm{~s}}$. After $\mathrm{F}$ air plasma of the PP meshes, a progressive increase of oxygen groups combined with a reduction of silicon is recorded.

In Fig. 3, the $\mathrm{C}_{1 \mathrm{~s}}$ high resolution XPS spectra of the UT, F-3.5s plasma-treated and PEG plasma-polymerized PP meshes are presented. It can be observed that the $\mathrm{C}-\mathrm{C}$ and $\mathrm{C}-\mathrm{H}$ bonds are predominant for the UT PP mesh (97.7\%) since the structure of PP includes only these atoms and type of bonding. Submitted to F air plasma treatment, the PP fibres undergo a progressive functionalization process of the fibre surface by $\mathrm{O}$ atoms through $\mathrm{C}-\mathrm{O}$ bonds with the plasma treatment time up to $6.8 \%$ for $3.5 \mathrm{~s}$ of plasma treatment $(\mathrm{F}-3.5 \mathrm{~s})$. The $\mathrm{C}_{1 \mathrm{~s}}$ peak decomposition of the PEG coated samples also revealed the introduction of $\mathrm{C}=\mathrm{O}$ and $\mathrm{COOH}$ functional groups on the surface of polypropylene.

\subsection{Influence of plasma treatment on the loading and release of ampicillin}

The ampicillin loading percentage of F plasma-treated PP meshes at different treatment times is presented in Fig. 4. UT PP presents low drug loading of only $20.8 \%$. With the increase of $\mathrm{F}$ plasma treatment time, loading progressively improves up to $59.5 \%$ for an air plasma treatment time of $3.5 \mathrm{~s}(\mathrm{~F}-3.5 \mathrm{~s})$. Longer plasma treatment times $(\mathrm{F}-7 \mathrm{~s})$ do not lead to a further improvement of the ampicillin loading, in parallel to the wetting behavior of plasma-treated PP. 
After ampicillin loading of the UT or F plasma-treated PP meshes, plasma polymerization was performed with tetraglyme to produce a thin PEG coating on the surface by means of a dry method. The total percentage of ampicillin released from the different PP meshes is shown in Fig. 5.

While the UT PP mesh presents an ampicillin release of $74.7 \%$, F-plasma treated PP fibres show slightly higher ampicillin release from the PP meshes, reaching values of 84.6\% for F-3.5s plasma-treated PP fibres without modification of the release kinetics with respect to the untreated mesh (burst release pattern was found in all cases - data not shown). UT+PEG-coated PP meshes display lower release values. Contrarily, F-3.5s after PEG plasma polymerization (F-3.5s + PEG), display the highest amount of drug released (Fig. 5).

\subsection{Influence of plasma treatment on the antibacterial activity}

To evaluate the antibacterial activity of ampicillin-loaded PP with the different plasma treatments, the inhibition areas were tested for Staphylococcus aureus and Escherichia coli (see Additional material 1). The method used allows a relatively quick and easy qualitative method to determine antibacterial activity of diffusible antimicrobial agents on treated textile materials $[34,35]$. Control samples without ampicillin did not show any inhibition area for UT, F plasma-treated or PEG-coated PP meshes.

Untreated PP mesh presents an inhibition area for S. aureus of $45.03 \pm 8.29 \mathrm{~mm}^{2}$ and no statistically significant differences were found among samples loaded with ampicillin with any of the treatments performed, confirming that antibacterial activity was preserved.

In the case of antibacterial activity of the ampicillin-loaded PP meshes tested for E. coli. an increase of the inhibition area for all the plasma-treated PP meshes was recorded with respect to the UT mesh, from $402.6 \pm 26.4 \mathrm{~mm}^{2}$ for untreated mesh to $752.4 \pm 45.4$ $\mathrm{mm}^{2}$ for $3.5 \mathrm{~s}$ F-plasma treatment $(\mathrm{F}-3.5 \mathrm{~s})$. This behavior can be related with the increased loading of ampicillin of the PP meshes obtained after functionalizing plasma treatment. After PEG plasma polymerization of the F-plasma treated PP meshes, this increased activity against $E$. coli is conserved.

\subsection{Influence of plasma treatment on topographical properties}

The topographical modifications introduced by $\mathrm{F}$ and/or PP plasma treatments have been investigated by SEM and AFM and the results are presented respectively in Fig. 6 and Fig. 7.

Fig. 7a reveals that the surface of UT PP is mainly flat showing a limited nanometric roughness, with an average roughness $\left(R_{R M S}\right)$ of $5.8 \mathrm{~nm}$. In the case of $F$ plasma 
treatment, important changes in roughness are observed with the longer plasma treatment time studied. While short plasma treatment times (F-0.35s) do not affect significantly the roughness regarding the UT sample, the value of mean roughness $\left(R_{R S M}\right)$ increased from $R_{R S M}=5.8 \mathrm{~nm}$ for the untreated PP mesh to $R_{R S M}=20.3 \mathrm{~nm}$ for the sample treated for F-1.75s with plasma and $R_{R S M}=18.3 \mathrm{~nm}$ for the F-3.5s plasma treatment (Fig. 7b).

\subsection{Influence of the plasma treatment on in vitro cell behavior}

The different surface chemistry, roughness, or ampicillin loading of the different PP meshes obtained by plasma treatments may have effects on processes related to the first step of host cell recruitment and infiltration during tissue repair. Thus, the influence of the F-plasma treatments, the ampicillin loading and the plasma PEG-coating has been evaluated on cell proliferation, chemotactic response, cell adhesion and morphology.

\subsubsection{Influence on the cell proliferation}

Influence of the initial preparation of the PP meshes has been studied on the growth medium used for the cell cultures. Thus, cell proliferation was quantified using THP1 monocytes (Fig. 8a) and NIH/3T3 fibroblasts (Fig. 8b) in contact with conditioned culture media generated from the different PP meshes to evaluate the biological response as an indicator of cellular properties of these materials.

The F-3.5s plasma treatment of the PP meshes does not alter significantly the THP-1 monocytes proliferation after 24 hours and slightly slows down the cell proliferation over 48 hours-assay without presenting cytotoxic effects (Fig. 8a). Incorporation of Ampicillin (AMP) does not alter monocyte proliferation, while the combination of plasma with drug loading (F-0.35+AMP) shows the greatest inhibition in THP1 cell growth. The PEG plasma coating limits this cytotoxicity, recovering to slightly better cell growth values, particularly after $72 \mathrm{~h}$.

No significant changes were observed in the cell growth of NIH-3T3 fibroblasts with reference to control at $24 \mathrm{~h}$ with any of the treatments evaluated (Fig. 8b). However, after $48 \mathrm{~h}$ samples with plasma PEG coating displayed a slight inhibition (between 12 and $30 \%$ depending on the treatment sequence) in cell proliferation with respect to the UT ones.

Although some treatments attenuate cell proliferation, no meshes induced cell death above that observed with the control, as quantified by means of an exclusion test with Trypan Blue (Additional material 2), and as also observed at the morphological level, where there is no suggestive change indicating cell death (Additional material 3). 


\subsubsection{Chemotactic response}

Chemotactic response has been studied for the different PP meshes using NIH-3T3 fibroblasts cultured in 2\% FBS growth medium (non-proliferation conditions), and the results are presented in Fig. 8c. These results were obtained using non-proliferative conditions to eliminate interference caused by the influence of the treatments on the cell proliferation.

Both UT PP meshes as well as the plasma-treated, ampicillin-loaded and PEG plasmacoated ones (F-3.5s + AMP+PEG) did not induce chemotaxis, showing similar levels to the negative control. All other treatments evaluated on PP meshes induced cell chemotaxis. The most significant difference was observed with the media conditioned by the ampicillin-loaded PP mesh, whether with or without previous F plasma treatment.

\subsubsection{Influence on the cell adhesion}

Unlike the previous cellular assays, cells were also cultured and incubated in direct contact with the PP materials to evaluate the influence of the PP mesh surface modification on the cell adhesion and morphology, using NIH-3T3 fibroblasts.

The cell adhesion on the F plasma-treated PP fibre surface and on UT+AMP-loaded ones decreased compared to what occurred in UT meshes, as can be observed in Fig. 9. In addition, fibroblasts adhered on F-3.5s PP fibres presented a more elongated morphology with respect to those attached on the UT PP.

On the contrary, the F plasma treatment prior to AMP loading returned the adhesion and cell morphology to levels observed with UT PP. The same behavior - although more scattered - is observed with the ampicillin-loaded PP meshes submitted to a subsequent PEG plasma-coating. The samples combining all treatments (F-3.5s + AMP+PEG) maintained cell adhesion levels as the UT meshes, although with a more round and compact cell morphology.

\section{DISCUSSION}

Given their good biocompatibility and mechanical properties, PP meshes are well established materials in the surgical repair of pathologies such as hernia. Hernia repair surgeries account for more than 1 million each year in the USA [36, 37]. The variety of meshes commonly used for hernia repair cover a range of polymer compositions, pore sizes, etc. the biocompatibility of which is determined by the extent of the patient's 
response to the implanted foreign body, as well as by the material characteristics of the mesh [38]. In the present study a macroporous polypropylene mesh currently employed in clinics was selected due to its medium weight which would allow better precision in recording drug loadings and release. Engelsman et al. [37] reviewed in 2007 a large number of clinical studies on infection rates of abdominal wall implants; surgery site infection rates for PP meshes range from 2 to $>5 \%$ [37-44]. Although the prevalence of infections is low, the burden associated therein justifies seeking for suitable ways to deliver antibiotics locally during the surgery. This would avoid the prophylactic systemic administration often performed prior/post-surgery. In this work, a dry technology (plasma) modifying only the first nanometres of the surface of the PP meshes without altering its mechanical properties is investigated as a novel way for incorporating high amounts of antibiotics and maintaining the biological surface properties of the materials. Two different plasma processes have been investigated here: plasma functionalization and plasma polymerization.

Plasma functionalization (F) with air at atmospheric pressure showed time-dependant effects, both regarding chemical modification and topographical changes (Figs. 2, 6, 7 and Tables 1, 2). For instance, the treatment rendered the hydrophobic PP surface hydrophilic, dropping contact angle from $120^{\circ}$ down to $25^{\circ}$ (Fig. 2). This was related in part to surface cleaning of hydrocarbon contaminants, but mainly due to grafting of Oxygen moieties on the surface (Tables 1, 2). As shown by XPS, since the polypropylene structure does not include oxygen atoms in its formula $\left(\mathrm{CH}_{2}=\mathrm{CH}-\mathrm{CH}_{3}\right)$, it can be observed that a small percentage of Si is present on the UT fibre surface that can be attributed to some adsorbed contamination from silicone-containing compounds that can also justify the presence of oxygen. The increase of oxygen moieties can be attributed to a functionalization process of the fibre surface, while the reduction of silicon comes from the elimination of the remaining surfactants on the fibre surface from the initial washing of the PP fabrics.

In general, UT PP fibres present a smooth surface (Fig. 6 and 7), as also shown in previous works $[45,46]$. It can be observed that F-plasma treatment progressively increases the roughness of the surface, where nano-bumps appear. Similar effects were also described in a previous study on the modification of surface properties of PP films using glow discharge air plasma [47]. In that work, the surface roughness of the PP film increased after 2-10 min of plasma treatment and similar protrusions to those of the present work appear. In their case, for long plasma treatment times (10-20 min) the protruding spikes got flattened due to continued etching.

The particular morphology of the nanostructures created by F plasma treatment on the PP surface does not directly correspond to etching of the polymer - as recorded with other polymers [23, 48] -, but agrees to more complex mechanisms related to polymer degradation. In fact, as shown in previous works [49-51], different mechanisms are taking place on the amorphous regions of the polymer; Combined etching processes, photo oxidation and thermal oxidation. The energy transferred to the polymer thermally 
and from UV-VIS by the F plasma employed acts as a reaction initiator on the weakest regions of the polymer (ie. amorphous regions in between spherulites) which is then continued and enhanced by the presence of $\mathrm{O}$ and $\mathrm{N}$ radicals, as well as by the highly reactive $\mathrm{O}_{3}$ also present in the plasma.

On loading these PP meshes with ampicillin a significant increase was recorded following F plasma treatments. Short treatment times $(0.35-1.75 \mathrm{~s})$ showed a 2-fold increase which can be attributed to the improved surface wettability, while longer times (3.5-7 s) loaded even higher amounts, up to $60 \%$, corresponding to 3 -fold the weight percentage loaded by the UT PP. In this case, in addition to the improved wettability after $\mathrm{F}$ plasma treatment due to the grafting of new $\mathrm{C}-\mathrm{O}$ bonds, the major specific surface area given by the higher roughness implies a higher availability of bonding sites (through $\mathrm{H}$-bonds) regarding the loading of the drug, in this case ampicillin.

Plasma polymerization using Tetraglyme as monomer led to obtaining thin layers of PEG-like polymer on the surface of PP. This was shown by contact angle (Fig. 2) and XPS results, where the decomposition of the $\mathrm{C}_{1 \text { s }}$ peak (Table 2) revealed that 4 different carbon bindings [52] can be found on the PEG and F-3.5s+PEG PP samples, in contrast to only 2 in the UT or F-plasma treated ones. The ether peak is indicative of the PEG character of the coating, and can be related to the fragmentation process during the plasma polymerization [53-55].

The contact angle values obtained here were slightly lower than the ones found in the literature for PEG plasma layers obtained from different monomers [56-60]. However, previous works [61] depositing PEG on Titanium from the same Tetraglyme monomer and similar discharge characteristics obtained contact angles ranging between 10 and $30^{\circ}$. In the present paper UT PP submitted to polymerization (PEG) yielded similar wettability (Fig. 2), with contact angle around $10^{\circ}$. When the sample had undergone a previous $\mathrm{F}$ plasma treatment $(\mathrm{F}-3.5 \mathrm{~s}+\mathrm{PEG})$, the value decreased down to $0^{\circ}$, reflecting perfect wettability, probably related to the combined effects of functionalization and enhanced roughness. While plasma polymerization of the UT PP did not affect the topography, with a $\mathrm{R}_{\mathrm{RSM}}=6.8 \mathrm{~nm}$, the effect of plasma polymerization process on the surface topography of the $\mathrm{F}$ plasma-treated sample is enhanced by the plasma polymerization treatment (Fig. 9 e,f and $10 \mathrm{c}, \mathrm{d}$ ). The roughness still increased up to $\mathrm{R}_{\mathrm{RSM}}=30.2 \mathrm{~nm}$ and the patterns obtained reveal preferential etching processes are taking place simultaneously to the coating deposition, which lead to well defined nanorough patterns.

The drug release pattern from the UT or F-3.5s plasma treated PP meshes was unaltered by the PEG plasma treatments (data not shown), which can possibly be explained by the thickness of the PEG layer. The thin layer of polymer obtained can be ascribed to the low vapour pressure of the monomer employed, tetraglyme, so in future works other PEG-forming monomers will be investigated to obtain thicker layers which may also help regulating the drug release [62-66]. Critically, the total amount of ampicillin 
loaded on the F-plasma treated materials is much higher than without the plasma treatment (nearly three-fold), and is related to higher released amounts (around $10 \mathrm{mg}$ ) from the F-3.5s and F-3.5s+PEG meshes, which may be very beneficial in views of local treatment. The antibacterial activity of the antibiotic released was conserved unaltered by the plasma treatments perfomed (Supplementary material 1). The Minimum Inhibitory Concentration (MIC) of Staphylococcus Aureus is much lower than that of Escherichia coli $\left(\mathrm{MIC}_{\mathrm{SA}}=0.03 \square \mathrm{g} / \mathrm{mL}[67]<<\mathrm{MIC}_{\mathrm{EColi}}=2-16 \square \mathrm{g} / \mathrm{mL}\right.$ [68]), which explains that in the former all samples overcome MIC and display the same inhibition areas, while in the latter the untreated sample has lower inhibition area than the rest of plasma treated samples with double and threefold times loading. Our approach differs from other works seeking antibacterial activity from textiles where plasma coatings are employed to prevent the release of the antibacterial agent (ie. Silver nanoparticles) to the surrounding media $[69,70]$.

PEG coatings for biomedical devices are intended to be non-toxic, antifouling and to show a decrease on the bacterial and cell adhesion. When the effects of meshconditioned media on cell proliferation and viability were compared (Fig. 8 a and b), those coming from either AMP or F-3.5s plasma-treated meshes did not induce significant changes, while conditioned medium from plasma polymerization treated meshes (PEG) inhibited cell growth at levels close to cytoxicity (in accordance with the ISO10993). The Trypan blue exclusion test (Additional material 2) ruled out any cytotoxic effect and under phase contrast microscope no cell morphological alterations nor cell damage was observed (see Additional material 3). These data provided evidence that the inhibition of cell proliferation in cells cultured with PEG-treated media was the result of a cytostatic effect rather than a cytotoxic mechanism. Junge et al. [71] reported good matching between the in vitro cytotoxicity and the in vivo biocompatibility of polyvinylidenfluoride (PVDF) meshes evaluated for infection prophylaxis by plasma-induced graft polymerization of polyacrylic acid. In close parallelism to our work, they also incorporated an antibiotic to the abdominal meshes and employed plasma processes for the surface modification. However their approach where the plasma-induced coating was aimed at providing grafting sites for the gentamicin. This is opposite to our case, where the PEG-coating obtained by plasma polymerization is carried out after ampicillin loading to confer the meshes with suitable biocompatibility.

One of the known techniques to eliminate surface "fouling" (or the random and unlimited adsorption of proteins to a surface has been the use of PEG-like surfaces, which have been prepared different methods, among which plasma deposition of tetraglyme [72,73]. These surface modifications not only avoid the unlimited adsorption of proteins, they also reduce monocyte, platelet and fibroblast adhesion in vitro [73-76]. The specific mechanism of how our PEG surfaces affect cell proliferation (and allowed cells to attach to their surface as well) remain unclear. Very few studies have addressed this specific issue; however, findings from in vitro studies suggest that these kind of surfaces are able to activate serum proteins present in the media such as the complement 
system through mechanisms that are still unclear [77]. We might think that other proteins able to modulate cell proliferation and present in the cell culture media could be modified by these surfaces. Moreover, previous reports suggest that despite displaying excellent non-adhesive properties in vitro, PEG coatings seem to have severe limitations in certain longer-term applications, such as the loss of their non-fouling character together with the presence of a high number of adherent inflammatory cells after long term in in vitro conditions [78, 79] or in vivo implantation [80]. This unexpected response has been ascribed to the oxidative degradation of PEG surfaces, which in our study could explain the anti-proliferative effects by hypothetically dissolved elements in the growth media and the observation of a substantial number of adhered cells after culturing them in direct contact with the meshes.

A polymer device should be able to provide a temporary scaffold that stimulates appropriate cellular and extracellular events that eventually improve wound healing [81]. In particular, in vivo mesh implantation is associated with increased cell recruitment, gelatinolytic activity, and neovasculogenesis, a host tissue response that dampens in a time-dependent manner [81, 82]. Within this context, the regulation of mobilility and recruitment of cells by chemotaxis are essential for recellularization and tissue regeneration.

Regarding our PP meshes, ampicillin-loaded meshes both untreated and F plasmatreated significantly stimulated in vitro NIH/3T3 migration exceeding that of the rest of surfaces, which may be related to the higher amount of ampicillin released into the medium by these two meshes compared with the ampicillin-loaded PEG-treated mesh. Dose-dependent effects of beta-lactams on several biological functions of eukariote cells have long been known [83], including the activation of chemotaxis in inflammatory cells $[84,85]$. Again, F-plasma treated ampicillin-loaded PEG-treated PP meshes (F-3.5s + AMP+PEG) did not elicit the same effect, but maintained the slight migratory effects observed with the untreated PP fibres leading us to conclude that the combination of these three treatments allowed maintaining the same chemotactic behavior of the PP fibres, thus justifying the relevance of the entire conditioning of the PP meshes by plasma processing.

Cell adhesion to extracellular matrix is another critical process that provides mechanical support and biochemical signals modulating tissue homeostasis and repair. In an analogous fashion, the surface properties of materials regulate cellular responses such as cell adhesion. The evidence of the lower cell adhesion in the F plasma-treated mesh (Fig. 9) emphasizes the predominance of the surface chemistry above the modification of the surface topography on the effects on cell behavior. Indeed, although higher roughness and improved wettability in these meshes can significantly influence cell adhesion and morphology - which was altered, with cells showing more elongated morphology, the increase in the surface amount of O-based chemical groups by means of plasma functionalization may have affected cell adhesion the opposite way, reducing it. It is well-known that ether groups are effective repelling cells and proteins and the 
increase of CO groups from $2.28 \%$ on the surface of the untreated PP mesh to $6.80 \%$ on 3.5 s F-plasma treated PP mesh (Table 2) could explain this decrease in cell adhesion [74]. Similarly, untreated AMP loaded meshes displayed low cell adhesion. Nevertheless, all of the PEG-coated PP meshes tended to recover cell adhesion to values close to the UT ones. Although the percentage of $\mathrm{CO}$ groups is similar and even higher than in F-plasma, other groups are found on the surface of the coated samples, such as ketone and carboxyl which surely play a role on the cell adhesion. Although the mechanisms are not yet clear, this is in line with previous works of Buxadera et al. [61] showing that tetraglyme plasma-deposited coatings in very similar conditions on Ti did not significantly affect fibroblast adhesion while showing antifouling and low bacterial adhesion properties. These results point out the suitable biocompatibility of the novel materials designed in here, and open the door for evaluating tissue integration in vivo in future studies.

The effects observed are summarized in Fig. 10. Thus, the combined treatment presented here (F-3.5s + AMP + PEG) allows the design of PP meshes with much higher AMP loadings and maintaining essentially unchanged fibroblast properties such as chemotaxis or adhesion with respect to UT meshes. This is highly desirable as these PP meshes have shown good clinical behavior and may contribute to improving patient comfort (through the local treatment, avoiding systemic antibiotic administration) and avoiding infections (thus decreasing economic burden).

\section{CONCLUSIONS}

In this work, two different plasma processes (Plasma Functionalization and Plasma Polymerization) are employed in a novel approach to design PP meshes for the prophylaxis and local treatment of infections in hernia repair. Plasma functionalization at atmospheric pressure has been used to modify PP fibre surfaces at a nanometric level, by functionalizing the surface with polar oxygen groups. These are related to a progressive increase of wettability as well as surface roughness dependent on the exposure time. The chemical and morphological changes produced on the surface of PP fibres allowed a better availability of bonding sites for subsequent attachment of molecules are related to nearly 3 -fold higher ampicillin loading in the PP meshes after only $3.5 \mathrm{~s}$ of $\mathrm{F}$ plasma treatment. However, these treatments alone were related with lower fibroblast adhesion, altered morphology and enhanced chemotaxis. Thus, the plasma-functionalized PP meshes containing high antibiotic loads were plasma-coated to obtain a nanometric polyethylene glycol-like layer (F-3.5s + AMP + PEG) that allowed combining higher AMP loadings and maintaining essentially unchanged fibroblast properties such as chemotaxis or adhesion with respect to UT meshes. As determined by bacterial assays with E. coli and S. aureus, the biological activity of the antibiotic was conserved after the different plasma treatments performed on the fabrics. 


\section{AKNOWLEDGMENTS}

Authors acknowledge L'Oreal-Unesco programme for Women in Science, the Spanish Government for financial support through Ramon y Cajal fellowship of CC, Generalitat de Catalunya through SGR 2014-1075 and SGR 2014-1333, the Slovenian Research Agency (ARRS) and the European Commission through Cost Action MP1101 "Bioplasmas".

\section{REFERENCES}

[1] Engelsman AF, Van der Mei HC, Ploeg RJ, Busscher HJ. The phenomenon of infection with abdominal wall reconstruction. Biomaterials 2007;28:2314-2327.

[2] Matthews BD, Pratt BL, Pollinger HS, Backus CL, Kercher KW, Sing RF, Heniford BT. Assessment of adhesion formation to intra-abdominal polypropylene mesh and polytetrafluoroethylene mesh. J Surg Res 2003;114:126-132.

[3] Wong JU, Leung TH, Huang CC, Huang CS. Comparing chronic pain between fibrin sealant and suture fixation for bilayer polypropylene mesh inguinal hernioplasty: a randomized clinical trial. Am J Surg 2011;202:34-38.

[4] Deeken CR, Abdo MS, Frisella MM, Matthews BD. Physico-mechanical evaluation of polypropylene, polyester, and polytetrafluoroethylene meshes for inguinal hernia repair. J Am Coll Surg 2011;212:68-79.

[5] Hung MJ, Liu FS, Shen PS, Chen GD, Lin LY, Ho ESC. Analysis of two sling procedures using polypropylene mesh for treatment of stress urinary incontinence. Int $\mathrm{J}$ Gynecol Obstet 2004;84:133-141.

[6] Siniscalchi R, Palma P, Riccetto C, Maciel LC, Ens G, Del Fabbro I. Biomechanical effects of the inclusion of holes to facilitate the integration in monofilament polypropylene meshes: An experimental study. Actas Urol Esp 2011;35:599-604.

[7] Harth KC, Rosen MJ, Thatiparti TR, Jacobs MR, Halaweish I, Bajaksouzian S, Furlan J, Von Recum HA. Antibiotic-releasing mesh coating to reduce prosthetic sepsis: An in-vivo study. J Surg Res 2010;163:337-343.

[8] 'Hernias.',[Online]. Available: http://emedicine.medscape.com/article/775630overview. [Accessed: 23-Dec-2014].

[9] Leber GE, Garb JL, Alexander AI, Reed WP. Long term complications associated with prosthetic repair of incisional hernias. Arch Surg 1998;13:378-382. 
[10] Bratzler DW, Dellinger EP, Olsen KM, Perl TM, Auwaerter PG, Bolon MK, Fish DN, Napolitano LM, Sawyer RG, Slain D, Steinberg JP, Weinstein RA. Clinical practice guidelines for antimicrobial prophylaxis in surgery. Am J Health Syst Pharm 2013;70:195-283.

[11] Yerdel MA, Akin EB, Dolalan S, Turkcapar AG, Pehlivan M, Gecim IE, Kuterdem E. Effect of single-dose prophylactic ampicillin and sulbactam on wound infection after tension-free inguinal hernia repair with polypropylene mesh: the randomized, doubleblind, prospective trial. Ann Surg 2001;233:26-33.

[12] Celdran A, Frieyro O, de la Pinta JC, Souto JL, Esteban J, Rubio JM, Señarís JF. The role of antibiotic prophylaxis on wound infection after mesh hernia repair under local anesthesia on an ambulatory basis. Hernia 2004;8:20-22.

[13] Tzovaras G, Delikoukos S, Christodoulides, Spyridakis JM, Mantzos F, Tepetes K, Athanassiou E, Hatzitheofilou C. The role of antibiotic prophylaxis in elective tensionfree mesh inguinal hernia repair: results of a single-centre prospective randomised trial. Int J Clin Pract 2007;61:236-239.

[14] Laurent T, Kacem I, Blanchemain N, Cazaux F, Neut C, Hildebrand HF, Martel B. Cyclodextrin and maltodextrin finishing of a polypropylene abdominal wall implant for the prolonged delivery of ciprofloxacin. Acta Biomaterialia 2011;7:3141-3149.

[15] Guillaume O, Garric X, Lavigne JP, Van Den Berghe H, Coudane J. Multilayer, degradable coating as a carrier for the sustained release of antibiotics: Preparation and antimicrobial efficacy in vitro. J Control Release 2012;162:492-501.

[16] Nisticò R, Faga MG, Gautier G, Magnacca G, D’Angelo D, Ciancio E, Piacenza G, Lamberti R, Martorana S. Physico-chemical characterization of functionalized polypropylenic fibres for prosthetic applications. Appl Surf Sci 2012;258:7889- 7896.

[17] Höcker H. Plasma treatment of textile fibres. Pure Appl Chem 2002;74(3): 423427.

[18] Grace JM, Gerenser LJ. Plasma treatment of polymers. J Dispers Sci Technol 2003;24:305-341.

[19] Hegemann D, Brunner H, Oehr C. Plasma treatment of polymers for surface and adhesion improvement. Nucl. Instr. Meth. Phys. Res. B 2003;208:281-286.

[20] Yoo HS, Kim TG, Park TG. Surface-functionalized electrospun nanofibres for tissue engineering and drug delivery, Adv. Drug Delivery Rev., 2009;61:1033.

[21] Denes FS, Manolache S. Macromolecular plasma-chemistry: an emerging field of polymer science. Prog Polym Sci 2004;29:815-885. 
[22] Yaman C, Özdoğan E, Seventekin N, Ayhan H. Plasma treatment of polypropylene fabric for improved dyeability with soluble textile dyestuff, Appl. Surf. Sci., 2009;255: 6764.

[23] Labay C, Canal C, García-Celma MJ. Influence of corona treatment on plasma PP and PA 6.6 on the release of a model drug. Plasma Chem Plasma P 2010;30:885-896.

[24] Labay C, Canal JM, Canal C. Relevance of surface modification of PA 6.6 fibres by air plasma treatment on the release of caffeine. Plasma Process Polym 2012;9:165173.

[25] Yasuda H. Plasma polymerization. Academic Press, Orlando, Florida, USA, 1985.

[26] Hegemann D. Plasma polymerization and its applications in textiles, Indian J Fibre Text 2006;31:99-115.

[27] Boyd RD, Kenwright AM, Badyal JPS, Briggs D. Atmospheric nonequilibrium plasma treatment of biaxially oriented polypropylene. Macromolecules 1997;30:54295436.

[28] Canal C, Molina R, Bertran E, Erra P. Wettability, ageing and recovery process of plasma treated polyamide 6. J. Adhesion Sci Technol 2004;18:1077-1089.

[29] Canal C, Molina R, Bertran E, Navarro A, Erra P. Effects of low temperature plasma on wool and wool/nylon blend dyed fabrics. Fibre Polym 2008;9(3):293-300.

[30] United States Pharmacopeia and National Formulary. Dissolution. Rockville, MD: US Pharmacopeial Convention; 2008. p. 267-274.

[31] Washington C. Drug release from microdisperse systems: A critical review. Int J Pharm 1990;58:1-12.

[32] Brack N, Lamb R, Pham D, Turner P. Effect of water at elevated temperatures on the wool fibre surface. Surf Interface Anal1999;27:1050-1054.

[33] Tsuchiya S, Yamabe M, Yamaguchi Y, Kobayashi Y, Konno T, Tada K. Establishment and characterization of a human acute monocytic leukemia cell line (THP-1). Int. J. Cancer 1980;26:171-176.

[34] Canal C, Gaboriau F, Villeger S, Cvelbar U, Ricard A. Studies on antibacterial dressings obtained by fluorinated post-discharge plasma. Int J Pharm 2009;367:155161.

[35] Pinho E, Magalhães L, Henriques M, Oliveira R. Antimicrobial activity assessment of textiles: standard methods comparison. Ann Microbiol 2011;61:493-498.

[36] Rutkow IM. Surgical operations in the United States. Then (1983) and now (1994). Arch Surg 1997;132(9):983-90. 
[37] Engelsman AF, van der Mei HC, Ploeg RJ, Busscher HJ. The phenomenon of infection with abdominal wall reconstruction. Biomaterials 2007;28:2314-2327.

[38] Sanders DL, Kingsnorth AN, Stephenson BM. Mosquito net mesh for abcominal wall hernioplasty: A comparison of material characteristics with commercial prosthetics. World J Surg 2013; 37: 737-745.

[39] Dunne JR, Malone DL, Tracy JK, Napolitano LM. Abdominal wall hernias: risk factors for infection and resource utilization. J Surg Res 2003;111(1):78-84.

[40] Andersson B, Hallen M, Leveau P, Bergenfelz A, Westerdahl J. Laparascopic extraperitoneal inguinal hernia repair versus open mesh repair: a prospective randomized controlled trial. Surgery 2003;133(5):464-72.

[41] Lal P, Kajla RK, Chander J, Saha R, Ramteke VK. Randomized controlled study of laparoscopic total extraperitoneal vs. open Lichtenstein inguinal hernia repair. Surg Endosc 2003;17:850-6.

[42] Sohail MR, Smilack JD. Hernia repair mesh associated Mycobacterium goodii infection. J Clin Microbiol 2004;42(6):2858-60.

[43] Neumayer L, Giobbie-Hurder A, Jonasson O, Fitzgibbons Jr R, Dunlop D, Gibbs J, et al. Open mesh versus laparoscopic mesh repair of inguinal hernia. N Engl J Med 2004;350(18):1819-27.

[44] Kulacoglu H. Hernia, Mesh, and Topical Antibiotics, Especially Gentamycin: Seeking the Evidence for the Perfect Outcome... Front Surg 2014;1:53.

[45] Wei Q, Wang Y, Wang X, Huang F, Yang S. Surface nanostructure evolution of functionalized polypropylene fibres. J Appl Polym Sci 2007;106:1243-1247.

[46] Gomathi N, Neogi S. Surface modification of polypropylene using argon plasma: Statistical optimization of the process variables. Appl Surf Sci 2009;255:7590-7600.

[47] Pandiyaraj KN, Selvarajan V, Deshmukh RR, Gao C. Modification of surface properties of polypropylene (PP) film using DC glow discharge air plasma. Appl Surf Sci 2009;255:3965-3971.

[48] Canal C, Gaboriau F, Molina R, Erra P, Ricard A. Role of the active species of plasmas involved in the modification of textile materials. Plasma Process Polym 2007;4:445-454.

[49] Poncin-Epaillard F, Brosse JC, Falher T. Cold plasma treatment: Surface or bulk modification of polymer films? Macromolecules 1997;30:4415-4420.

[50] Médard N, Soutif JC, Poncin-Epaillard F. Characterization of $\mathrm{CO}_{2}$ plasma-treated polyethylene surface bearing carboxylic groups. Surf Coat Tech 2002;160:197-205. 
[51] Fresnais J, Chapel JP, Poncin-Epaillard F. Synthesis of transparent superhydrophobic polyethylene surfaces. Surf Coat Tech 2006;200:5296-5305.

[52] Mutlu S, Çökeliler D, Mutlu M, Modification of food contacting surfaces by plasma polymerization technique. Part II: Static and dynamic adsorption behavior of a model protein "bovine serum albumin"' on stainless steel surface. J Food Eng 2007;78:494-499.

[53] Michelmore A, Gross-Kosche P, Al-Bataineh SA, Whittle JD, Short RD. On the effect of monomer chemistry on growth mechanisms of nonfouling PEG-like plasma polymers. Langmuir 2013:29;2595-2601.

[54] Michel R, Pasche S, Textor M, Castner DG. The influence of PEG architecture on protein adsorption and conformation. Langmuir 2005;21:12327-12332.

[55] Zhang M, Desai T, Ferrari M. Proteins and cells on PEG immobilized silicon surfaces, Biomaterials 1998; 19(10), 953-960.

[56] Kenawy ER, Worley SD, Broughton R. Chemistry and applications of antimicrobial polymers: a state-of-art review. Biomacromolecules 2007;8:1359-1384.

[57] Favia P, Creatore M, Palumbo F, Colaprico V, d'Agostino R. Process control for plasma processing of polymers. Surf Coat Technol 2001;1:142-144.

[58] Smith HB, Charles C, Boswell RW. Breakdown behavior in radio-frequency argon discharges, Phys Plasmas 2003:10;875-881.

[59] Burm KTAL. Calculation of the Townsend discharge coefficients and the paschen curve coefficients, Contrib Plasma Phys 2007;47:177-182.

[60] Pace JD, Parker AB. Electropolished and chemically cleaned stainless steel electrodes separated by 0.3 to $2.0 \mathrm{~cm}$. System backed to yield $10^{-8}$ Torr. J Phys D Appl Phys 1973;6:1525-1536.

[61] Buxadera-Palomero J, Canal C, Torrent-Camarero S, Garrido B, Gil FJ, Rodriguez D, Biointerphases. 2015;10(2) (In press).

[62] Bhatt S, Pulpytel J, Mirshahi M, Arefi-Khonsari F. Catalyst-free plasma-assisted

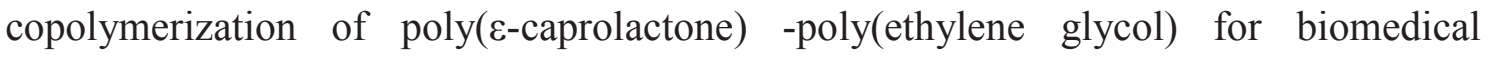
Applications. ACS Macro Letters 2012;1(6):764-767.

[63] Bhatt S, Pulpytel J, Mori S, Mirshahi M, Arefi-Khonsari F. Cell repellent coatings developed by an open air atmospheric pressure non-equilibrium argon plasma jet for biomedical Applications. Plasma Process Polym 2014;11(1):24-36.

[64] Bhatt S, Pulpytel J, Mirshahi M, Arefi-Khonsari F. Cell resistant peptidomimetic Poly (2-ethyl-2-oxazoline) coatings developed by low pressure inductively excited pulsed plasma polymerization for biomedical purpose. Plasma Process Polym 2015 (In Press). 
[65] Bhatt S, Pulpytel J, Mirshahi M, Arefi-Khonsari F. Plasma co-polymerized nano coatings - As a biodegradable solid carrier for tunable drug delivery applications. Polymer 2013;54(18):4820-4829.

[66] Canal C, Gallinetti S, Khurana K, Bhatt S, Pulpytel J, Arefi-Khonsari F, Ginebra MP. Regulation of simvastatin release from calcium phosphate scaffolds by plasma polymerization. 2015 (in preparation)

[67]

https://www.eurofinspanlabs.com/Catalog/Products/ProductDetails.aspx?prodId=EkmL qEprEIg\%3D

[68] Greenwood D, O'Grady F. A comparison of the effects of ampicillin on escherichia coli and proteus mirabilis. J. Med. Microbiol. 1969; 2:435-441.

[69] Deng X, Leys C, Vujošević D, Vuksanović V, Cvelbar U, De Geyter N, Morent R, Nikiforov A. Engineering of composite organosilicon thin films with embedded silver nanoparticles via atmospheric pressure plasma process for antibacterial activity. Plasma Process Polym 2014;11(10):921-930.

[70] Deng X, Nikiforov A, Vujosevic D, Vuksanovic V, Mugoša B, Cvelbar U, De Geyter N, Morent R, Leys C. Antibacterial activity of nano-silver non-woven fabric prepared by atmospheric pressure plasma deposition. Mater Lett 2015;149:95-99.

[71] Junge K, Rosch R, Klinge U, Krones C, Klosterhalfen B, Mertens PR, Lynen P, Kunzf D, Prei A, Peltroche-Llacsahuanga H, Schumpelick V. Gentamicin supplementation of polyvinylidenfluoride meshmaterials for infection prophylaxis. Biomaterials 2005; 26:787-793.

[72] López GP, Ratner BD, Tidwell CD, Haycox CL, Rapoza RJ, Horbett TA. Glow discharge plasma deposition of tetraethylene glycol dimethyl ether for fouling-resistant biomaterial surfaces. J Biomed Mater Res 1992; 26(4):415-39.

[73] Cao L, Chang M, Lee CY, Castner, DG, Sukavaneshvar S, Ratner BD, Horbett TA. Plasma-deposited tetraglyme surfaces greatly reduce total blood protein adsorption, contact activation, platelet adhesion, platelet procoagulant activity, and in vitro thrombus deposition. J Biomed Mater Res A 2007;81(4): 827-837.

[74] Valdes TI, Ciridon W, Ratner BD, Bryers JD. Surface modification of a perfluorinated ionomer using a glow discharge deposition method to control protein adsorption. Biomaterials 2008; 29(10):1356-66.

[75] Valdes TI, Ciridon W, Ratner BD, Bryers JD. Modulation of fibroblast inflammatory response by surface modification of a perfluorinated ionomer. Biointerphases 2011; 6(2):43-53. 
[76] Yang Z, Wang J, Li X, Tu Q, Sun H, Huang N. Interaction of platelets, fibrinogen and endothelial cells with plasma deposited PEO-like films. Appl Surf Sci $2012 ; 258: 3378-3385$.

[77] Szott LM, Stein MJ, Ratner BD, Horbett TA. Complement activation on poly (ethylene oxide)-like radiofrequency glow discharge-deposited surfaces, J Biomed Mater Res A, 2011;96(1):150-161.

[78] Branch DW, Wheeler BC, Brewer GJ, Leckband DE. Long-term stability of grafted polyethylene glycol surfaces for use with microstamped substrates in neuronal cell culture. Biomaterials, 2001;22(10):1035-47.

[79] Roosjen A, de Vries J, van der Mei HC, Norde W, Busscher HJ. Stability and effectiveness against bacterial adhesion of poly (ethylene oxide) coatings in biological fluids. J Biomed Mater Res B: Applied Biomaterials 2005;73(2):347-354.

[80] Shen M, Martinson L, Wagner MS, Castner DG, Ratner BD, Horbett TA. PEO-like plasma polymerized tetraglyme surface interactions with leukocytes and proteins: in vitro and in vivo studies. Journal of Biomaterials Science Polymer 2002;13(4):367-390.

[81] López-Cano M, Armengol M, Quiles MT, Biel A, Velasco J, Huguet P, Mestre A, Delgado LM, Gil FX, Arbós MA. Preventive midline laparotomy closure with a new bioabsorbable mesh: an experimental study. J Surg Res 2013; 181(1):160-9.

[82] Arbos MA, Ferrando JM, Quiles MT, Vidal J, López-Cano M, Gil J, Manero JM, Peña J, Huguet P, Schwartz-Riera S, Reventós J, Armengol M. Improved surgical mesh integration into the rat abdominal wall with arginine administration. Biomaterials 2006;27(5):758-68.

[83] Neftel KA, Hubscher U. Effects of 1-lactam antibiotics on proliferating eucaryotic cells. Antimicrob Agents Chemother 1987; 31(11): 1657-1661.

[84] Sebastian K, Ott H, Zwadlo-Klarwasser G, Skazik-Voogt C, Marquardt Y, Czaja K, Merk HF, Malte Baron J. Evaluation of the sensitizing potential of antibiotics in vitro using the human cell lines THP-1 and MUTZ-LC and primary monocyte- derived dendritic cells. Toxicol Appl Pharm 2012;262:283-292.

[85] Kwiatkowska B, Maslinska M, Przygodzka M, Dmowska-Chalaba J, Dabrowska J, Sikorska-Siudek K. Immune system as a new therapeutic target for antibiotics. Adv Biosci Biotechnol 2013; 4:91-101. 
Table 1: Surface elemental composition and atomic ratios of PP meshes with different functionalizing $(\mathrm{F})$ plasma or polymerizing $(\mathrm{PEG})$ plasma treatments.

\begin{tabular}{|c|c|c|c|c|c|}
\hline Samples & UT & F-1.75s & F-3.5s & UT+PEG & F-3.5s+PEG \\
\hline $\mathrm{C}_{1 \mathrm{~s}}$ & 84.0 & 84.2 & 79.7 & 83.8 & 81.2 \\
\hline $\mathbf{O}_{1 \mathrm{~s}}$ & 10.0 & 13.4 & 18.5 & 15.5 & 18.8 \\
\hline $\mathbf{N}_{1 \mathrm{~s}}$ & 0.3 & 0.1 & 0.7 & 0.1 & $<0.1$ \\
\hline $\mathrm{Si}_{2 p}$ & 5.8 & 2.3 & 1.1 & 0.6 & $<0.1$ \\
\hline $\mathrm{O} / \mathrm{C}$ & 0.12 & 0.16 & 0.23 & 0.18 & 0.23 \\
\hline
\end{tabular}


Table 1: Fraction of carbon functional groups from high-resolution $\mathrm{C}_{1 \mathrm{~s}}$ XPS peaks for untreated and plasma treated samples and of the same after PEG-coating for 1 hour by plasma polymerization.

\begin{tabular}{ccccc}
\hline \multirow{3}{*}{ Samples } & \multicolumn{4}{c}{ Relative chemical bonds (\%) } \\
\cline { 2 - 5 } & $284.76 \mathrm{eV}$ & $286.16 \mathrm{eV}$ & $287.22 \mathrm{eV}$ & $288.66 \mathrm{eV}$ \\
UT & $\mathrm{C}-\mathrm{C}, \mathrm{C}-\mathrm{H}$ & $\mathrm{C}-\mathrm{O}$ & $\mathrm{C}=\mathrm{O}$ & $\mathrm{COOH}$ \\
F-1.75s & 97.72 & 2.28 & - & - \\
F-3.5s & 96.74 & 3.26 & - & - \\
UT+PEG & 93.20 & 6.80 & - & - \\
F-3.5s+PEG & 86.80 & 6.64 & 2.29 & 4.27 \\
\hline
\end{tabular}


Table 1: Surface elemental composition and atomic ratios of PP meshes with different functionalizing $(\mathrm{F})$ plasma or polymerizing $(\mathrm{PEG})$ plasma treatments.

\begin{tabular}{|c|c|c|c|c|c|}
\hline Samples & UT & F-1.75s & F-3.5s & UT+PEG & F-3.5s+PEG \\
\hline $\mathrm{C}_{1 \mathrm{~s}}$ & 84.0 & 84.2 & 79.7 & 83.8 & 81.2 \\
\hline $\mathbf{O}_{1 \mathrm{~s}}$ & 10.0 & 13.4 & 18.5 & 15.5 & 18.8 \\
\hline $\mathbf{N}_{1 \mathrm{~s}}$ & 0.3 & 0.1 & 0.7 & 0.1 & $<0.1$ \\
\hline $\mathrm{Si}_{2 p}$ & 5.8 & 2.3 & 1.1 & 0.6 & $<0.1$ \\
\hline $\mathrm{O} / \mathrm{C}$ & 0.12 & 0.16 & 0.23 & 0.18 & 0.23 \\
\hline
\end{tabular}




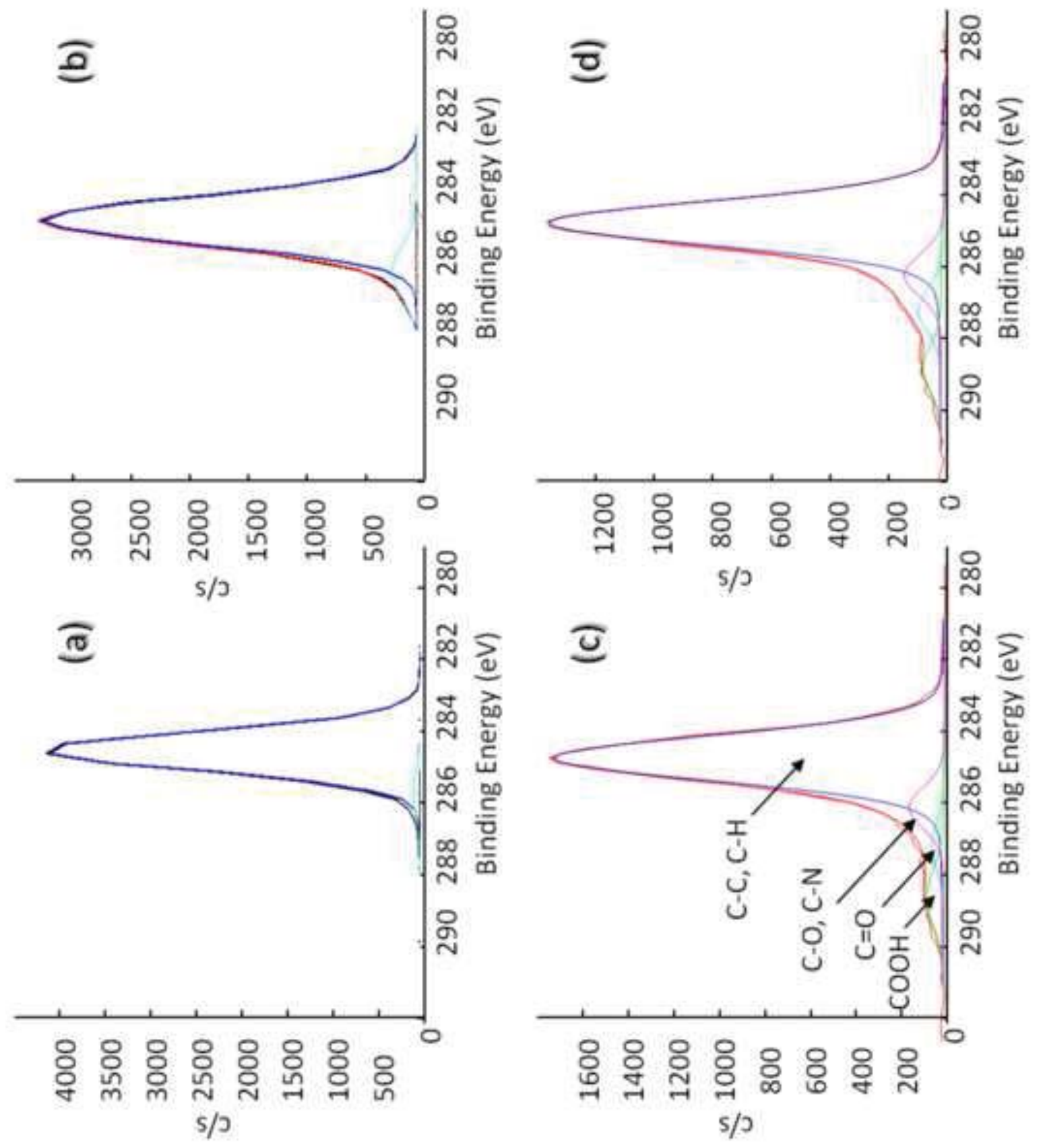




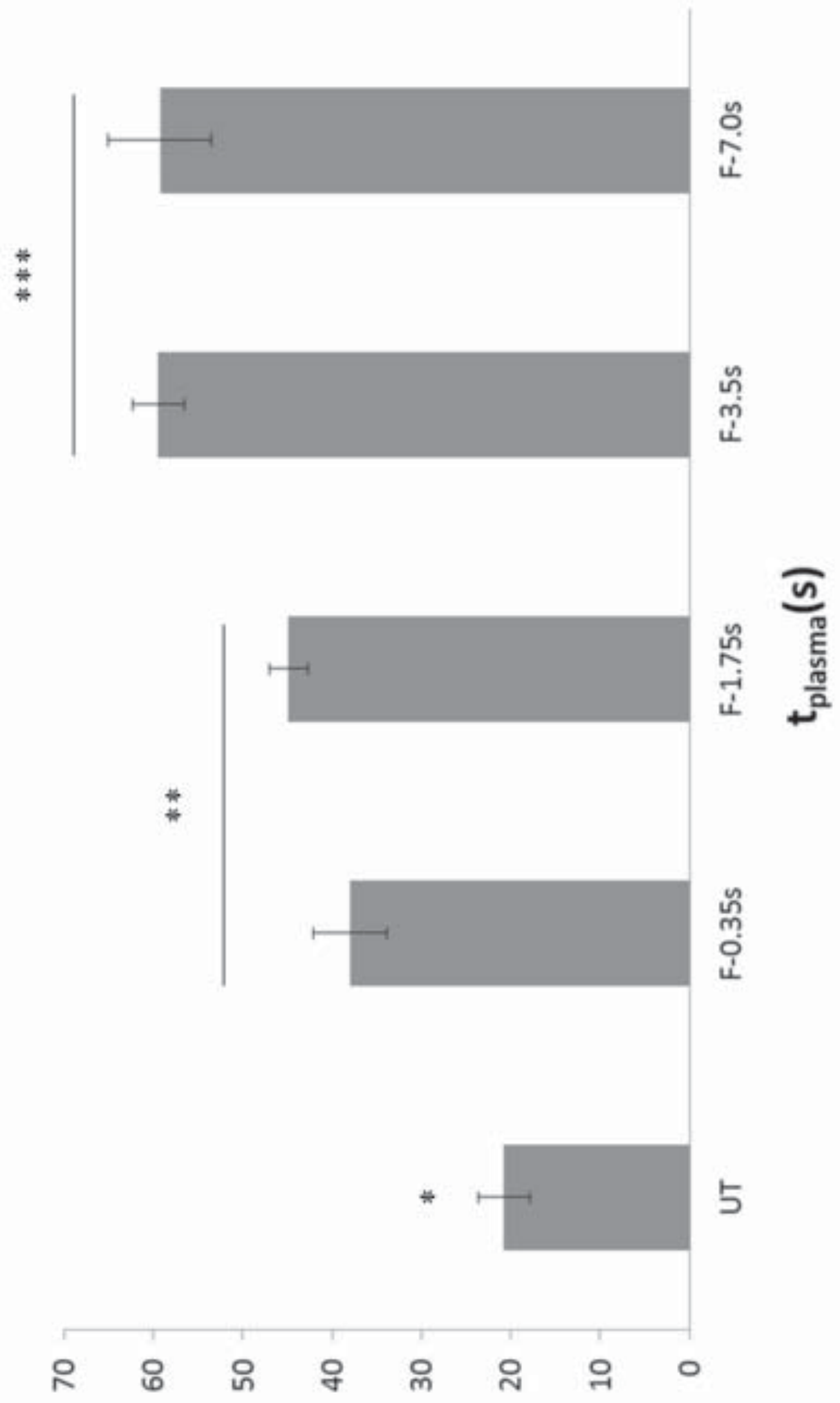

(\%) ชu!̣peo| u!!!!ฺ̣dur 


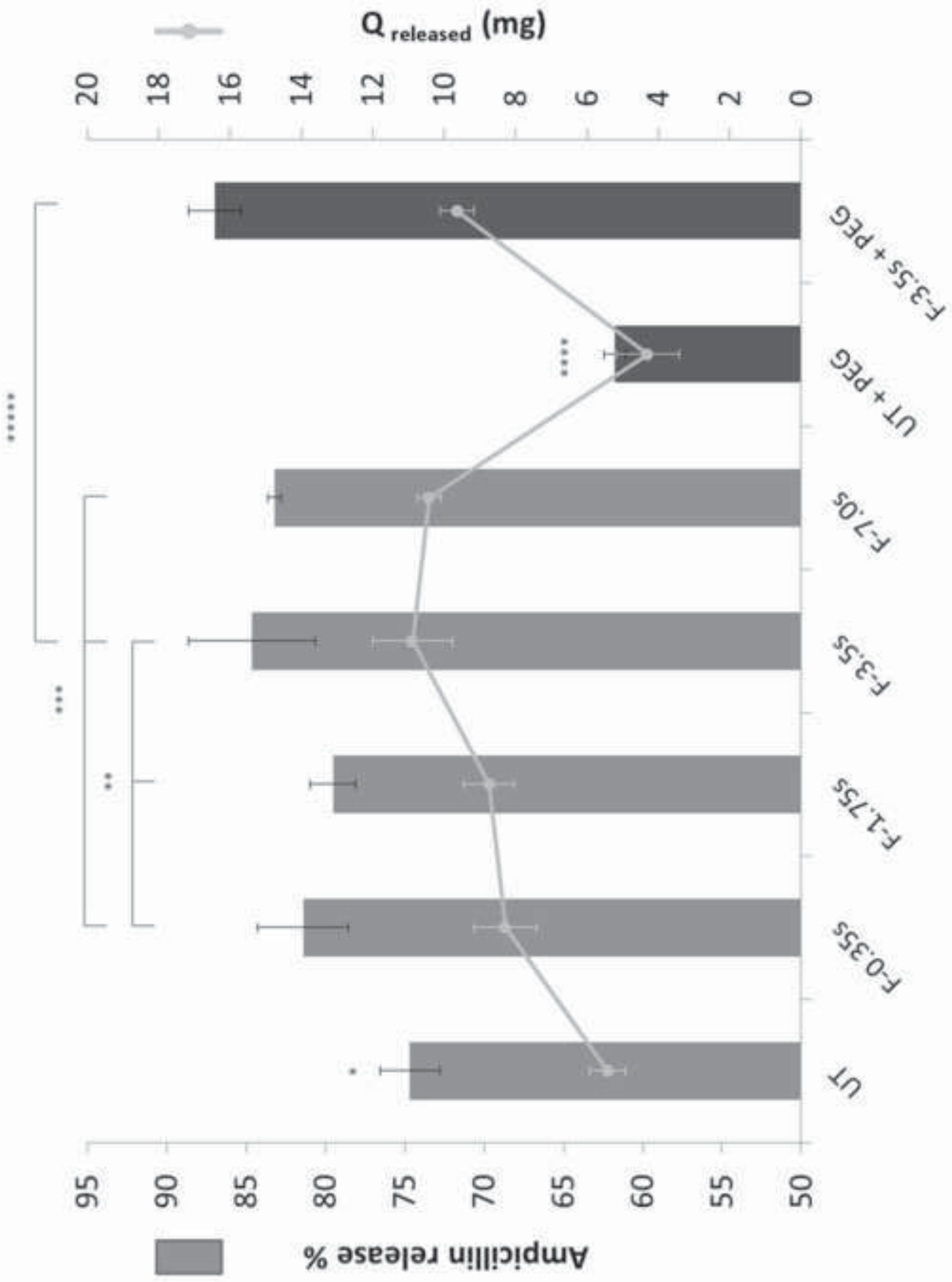




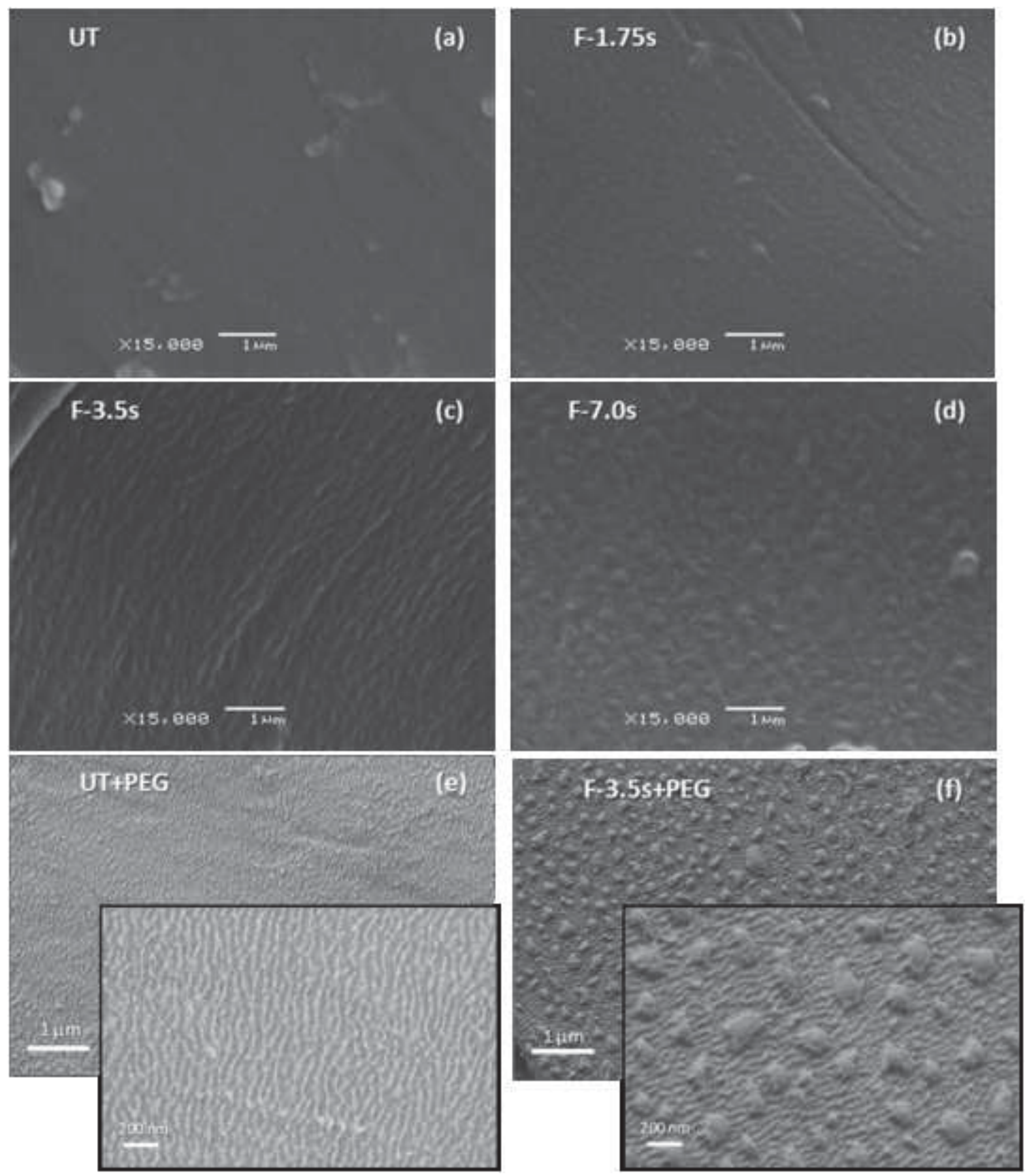



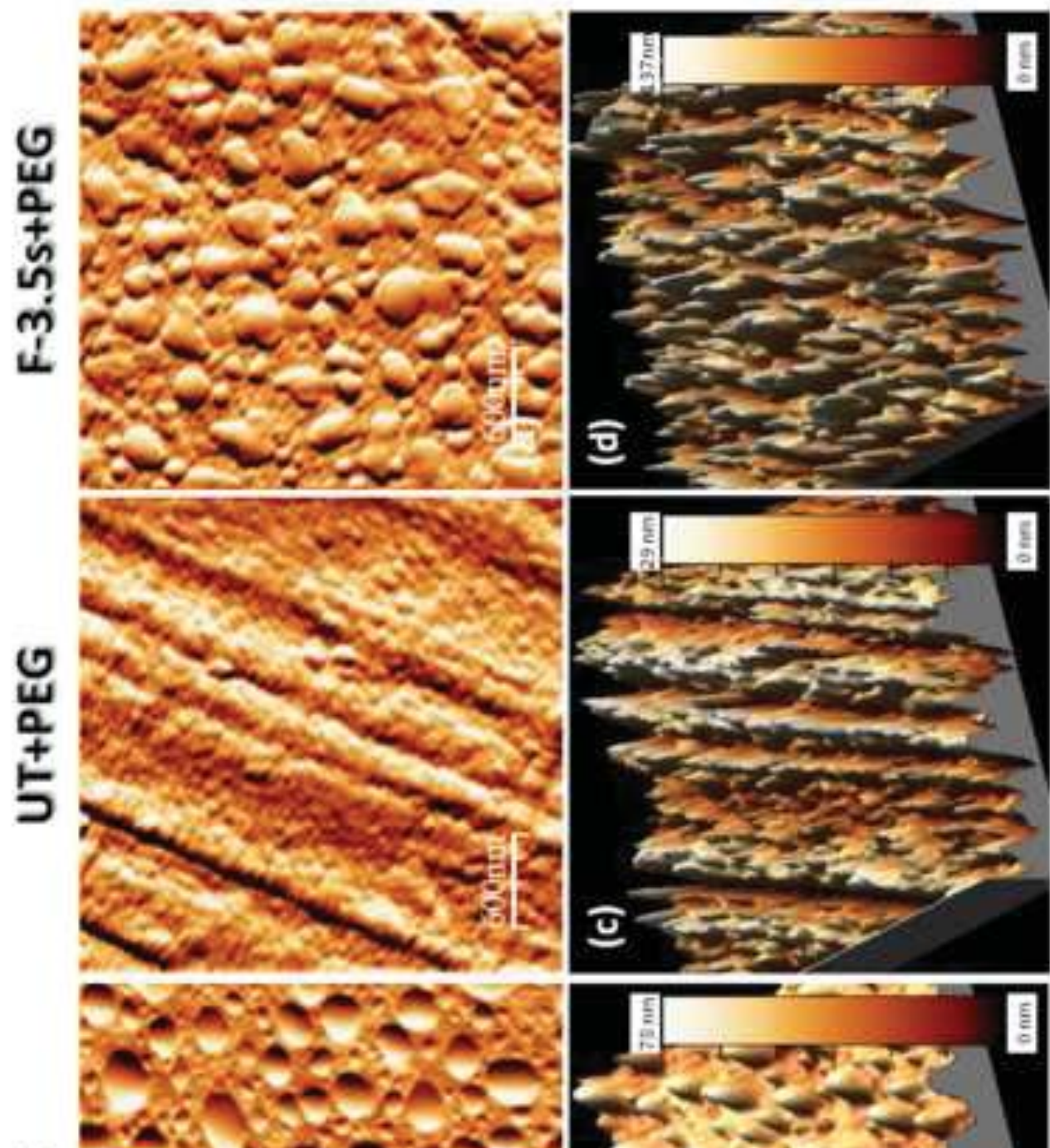

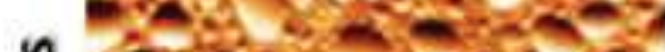

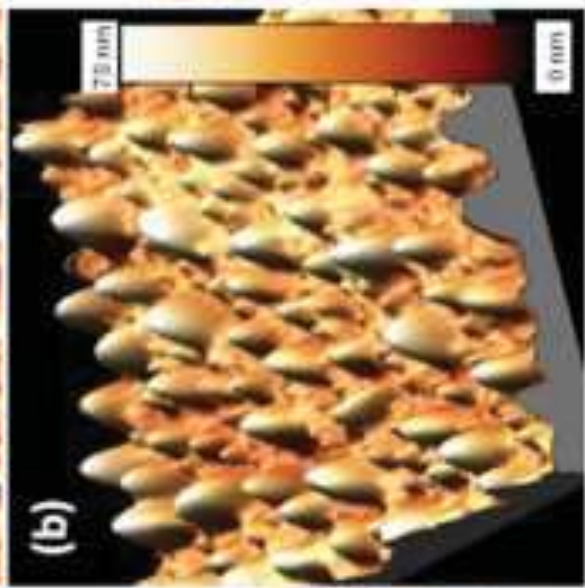

ตุ

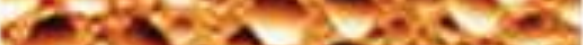

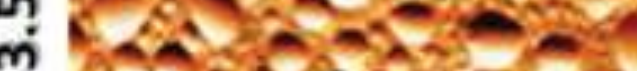

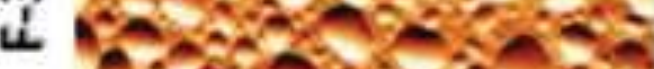

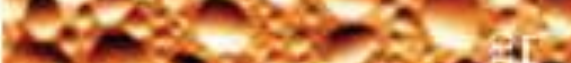

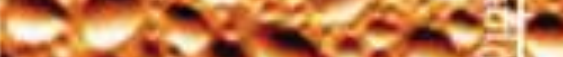

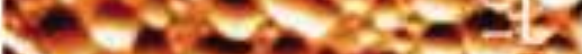

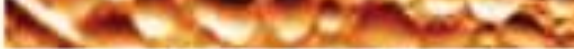
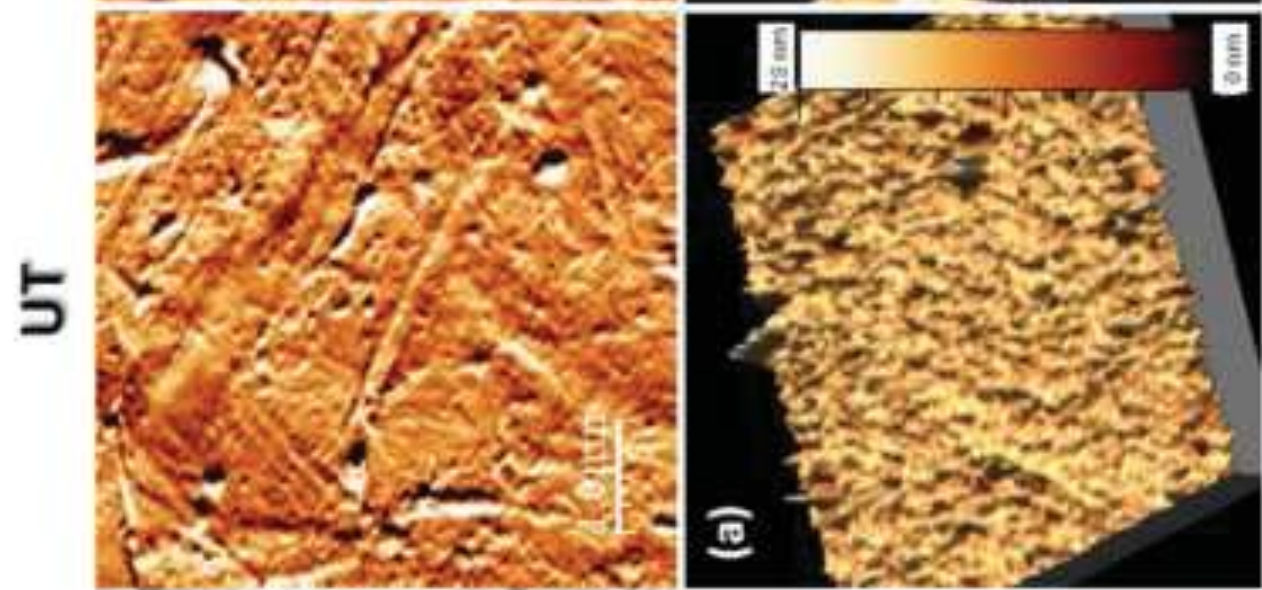

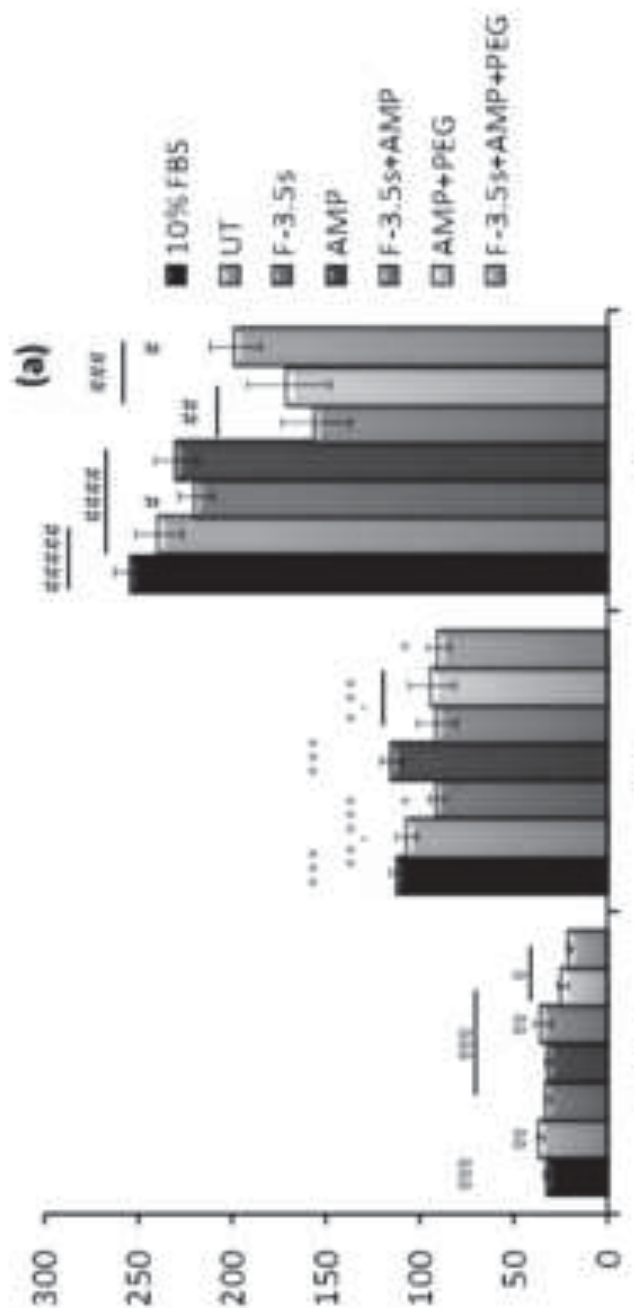

ч)М०ม8 ||әว\%
$\Xi \quad \vdots$

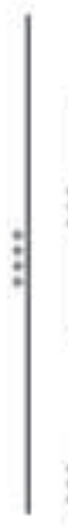
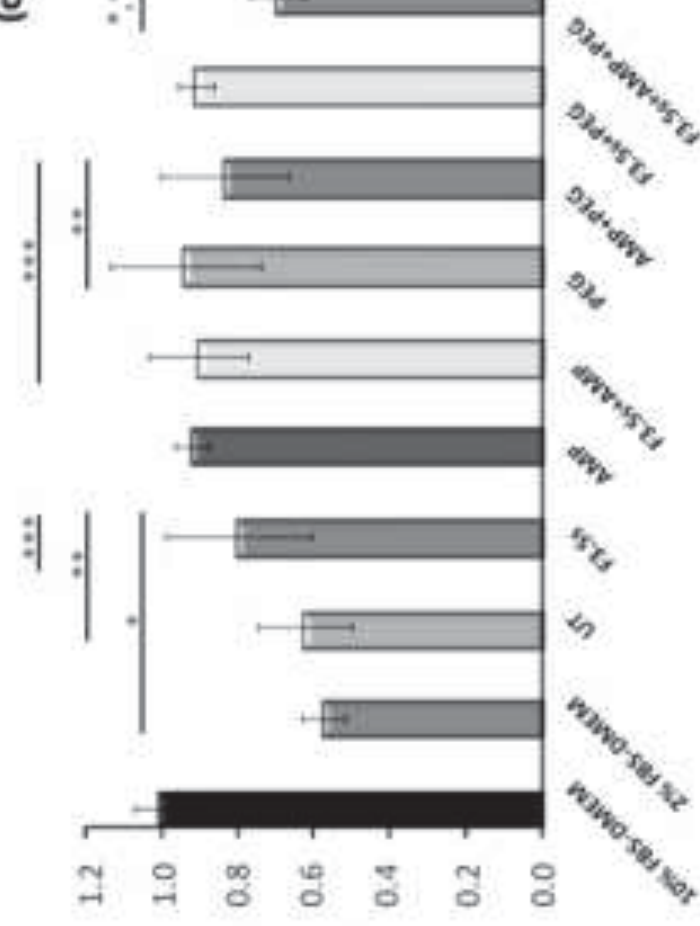

[onuop sh)

voเjes6iu jo e6ueqs pio

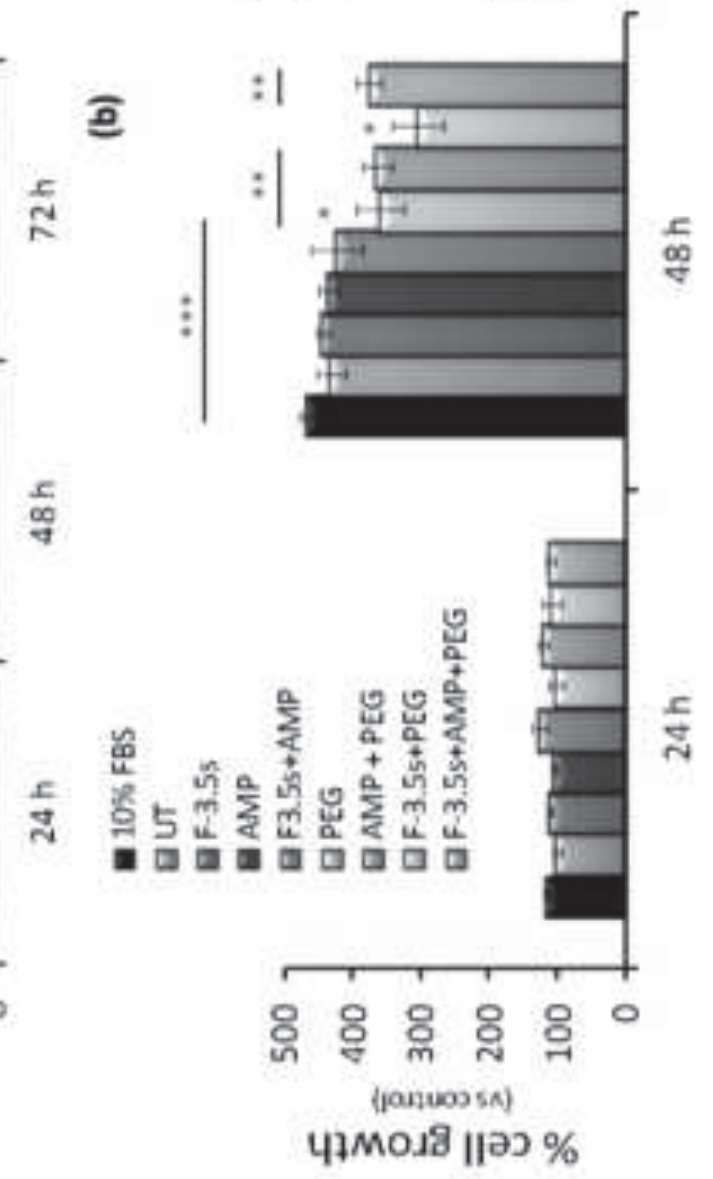



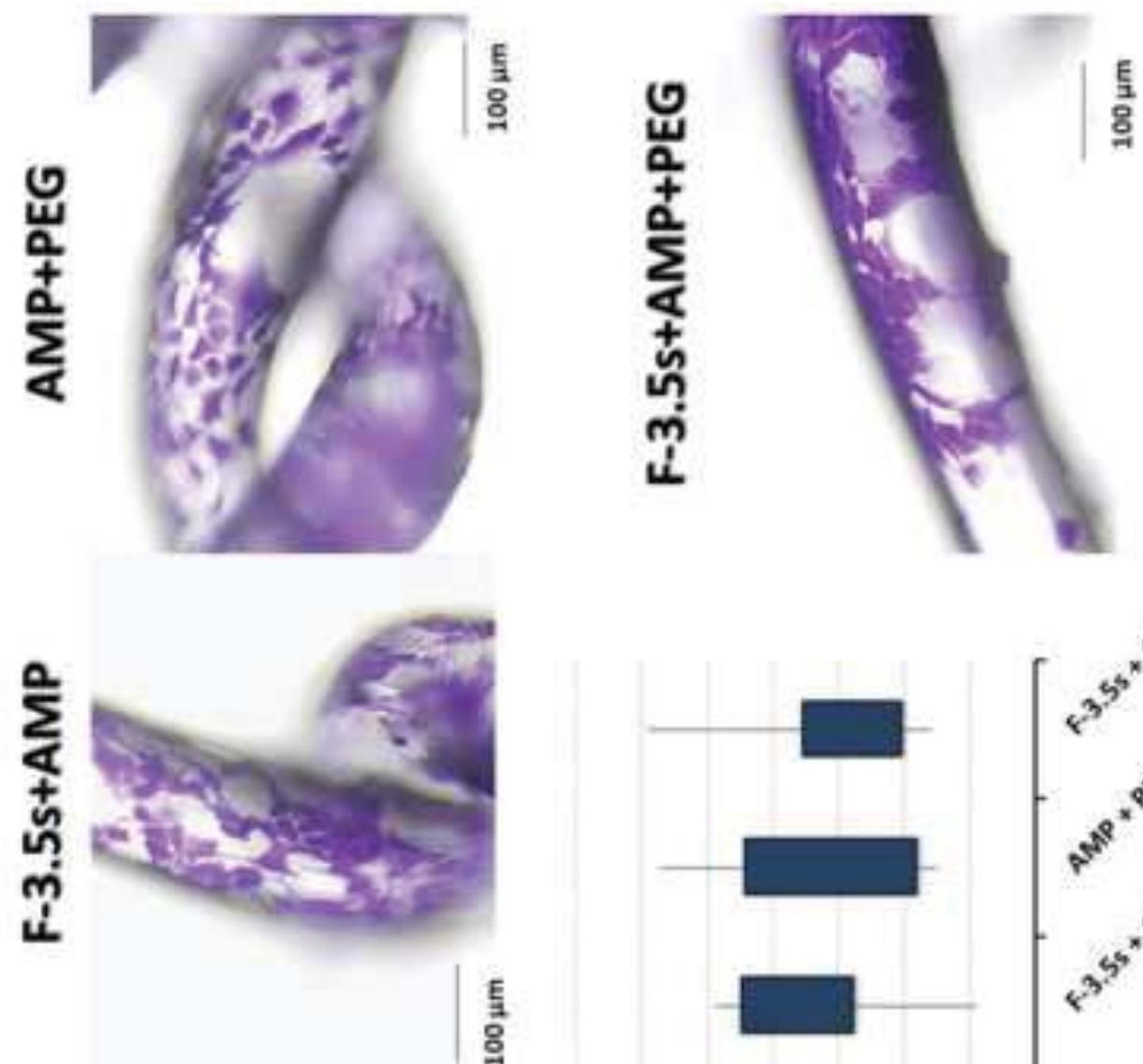

통
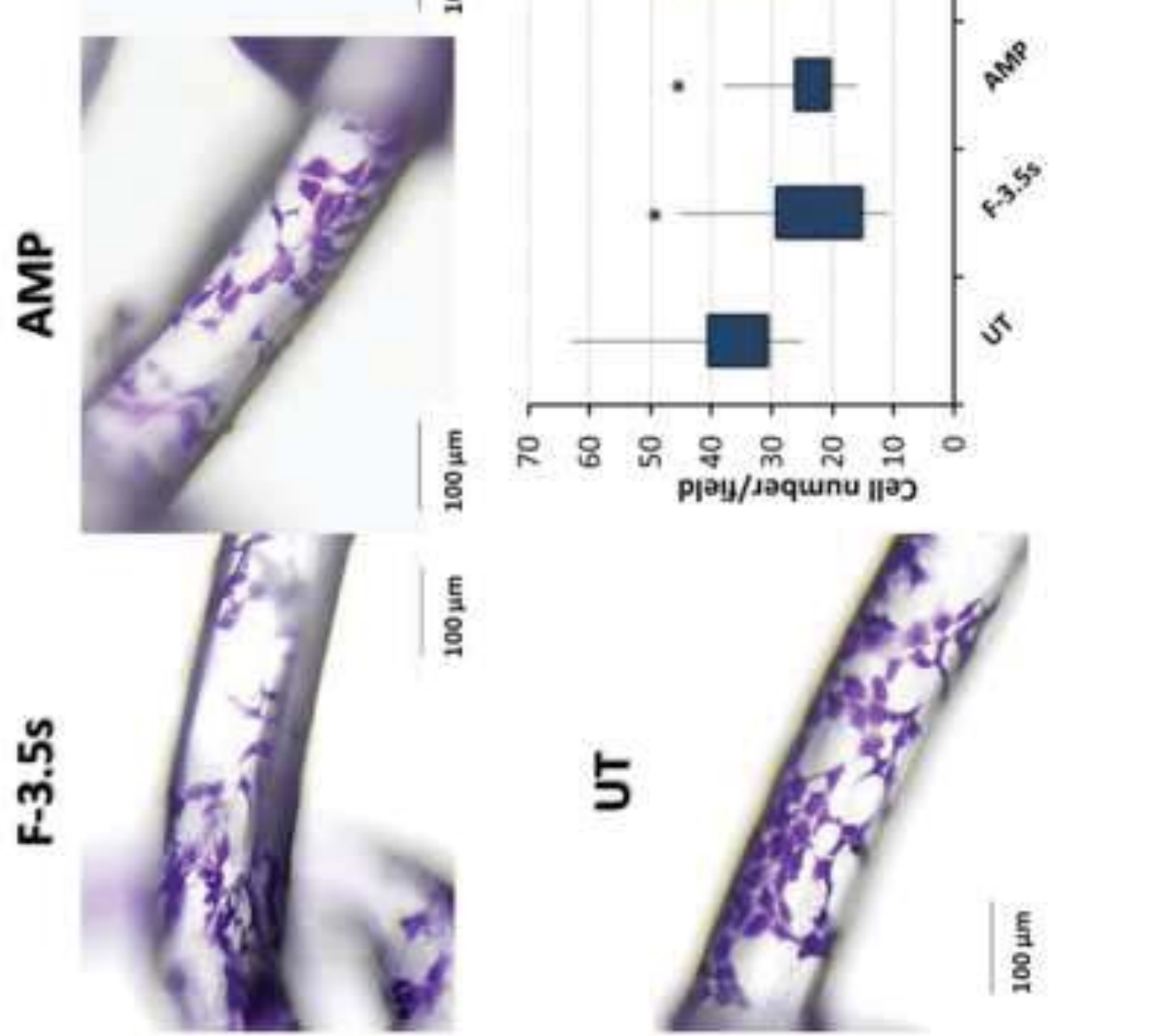


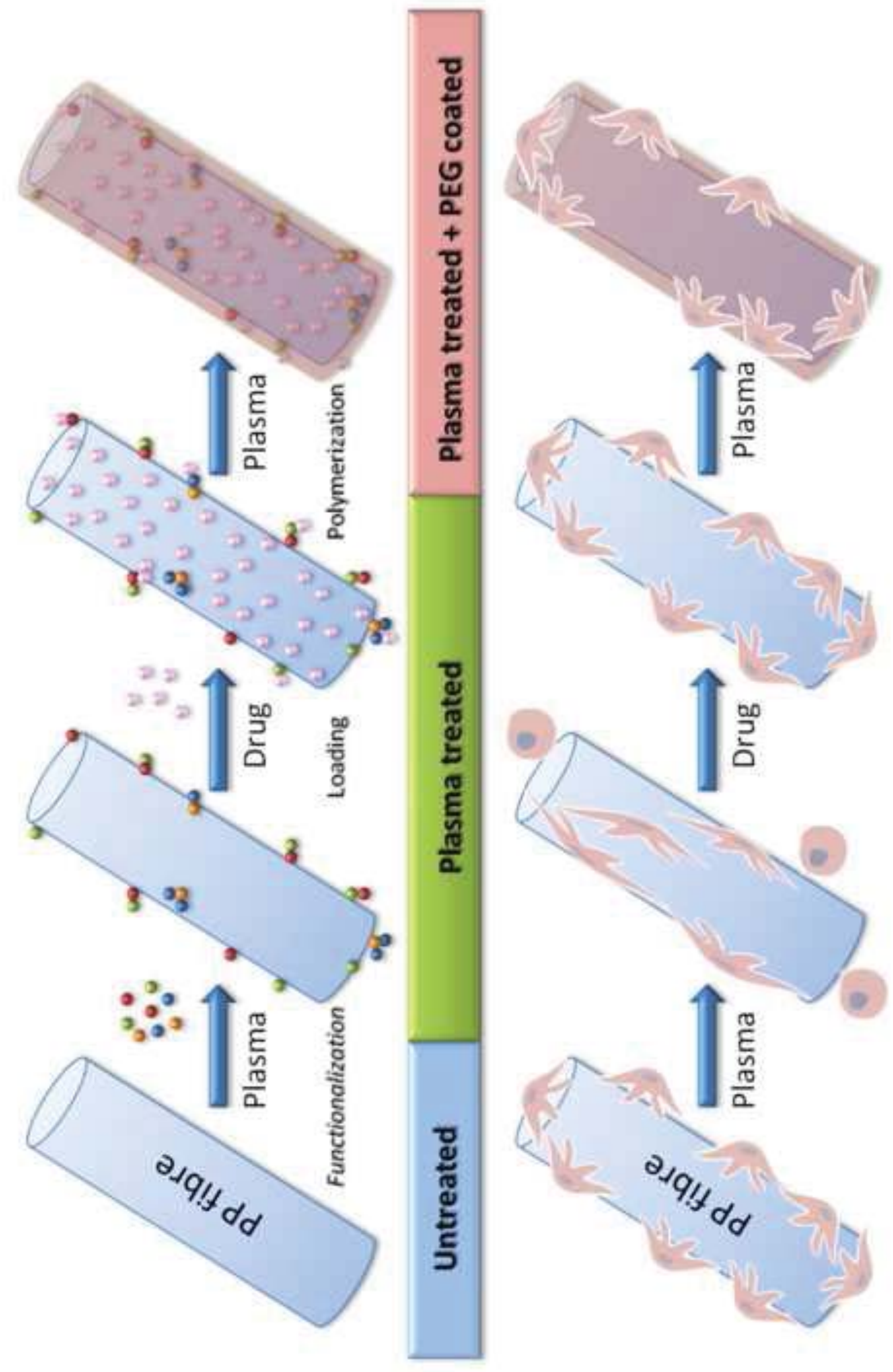




\section{Table captions}

Table 1: Surface elemental composition and atomic ratios of PP meshes with different functionalizing $(\mathrm{F})$ plasma or polymerizing (PEG) plasma treatments.

Table 2: Fraction of carbon functional groups from high-resolution $\mathrm{C}_{1 \mathrm{~s}}$ XPS peaks for untreated and plasma treated samples and of the same after PEG-coating for 1 hour by plasma polymerization.

\section{Figure Captions}

Figure 1. Experimental design for the design of enhanced surgical PP meshes through plasma functionalization treatments, antibiotic loading and plasma polymerization of PEG coatings, with detail of sample codes.

Figure 2. Water static contact angle as a function of plasma treatment time.

Figure 3. C1s high-resolution XPS spectra of UT (a) and F-3.5s plasma-treated PP meshes and their homologues after PEG plasma coating (c) PEG and (d) F-3.5s+PEG.

Figure 4. Ampicillin loading percentage of the PP meshes as a function of $\mathrm{F}$ air plasma treatment time. Different symbols indicate statistically significant differences $(p<0.05)$.

Figure 5. Cumulative ampicillin release percentage after $4 \mathrm{~h}$ and ampicillin amount released from UT, F - plasma-treated and PEG-plasma coated PP meshes. Different symbols indicate statistically significant differences $(p<0.05)$.

Figure 6. Scanning Electron Micrographs of UT (a), plasma-treated PP mesh F-1.75s (b) F-3.5s (c), F-7s (d) and after PEG plasma coating: UT+PEG (e) F-3.5s+PEG (f), with the corresponding magnification of (e) and (f).

Figure 7. AFM topography (top images) of the UT (a), F-3.5s plasma-treated (b) PP meshes, and after PEG plasma coating: UT+PEG (c) and F-3.5s+PEG (d), with the respective $3 \mathrm{D}$ reconstitutions of the fibre surface (bottom images).

Figure 8. Effects of cell growth media conditioned by the ampicillin-loaded or unloaded PP meshes with different surface treatments on cell proliferation and migration. (a) Assessment of cell number by cell counting in THP1 monocytes. Each time point is expressed as a relative value to time 0 . (b) NIH3T3 fibroblast cell growth evaluated by crystal violet staining. Time points are expressed as relative values to cells cultured with DMEM / 2\%FBS (negative control). (c) Assessment of NIH/3T3 migration index in in vitro transwell assay. Values represent the average and bars represent S.D of two independent experiments carried out each time in triplicates. Different symbols indicate statistically significant differences $(\mathrm{p}<0.05)$. 
Figure 9. Adhesion and cell morphology assessment of NIH/3T3 fibroblasts cultured on a) UT, b) F-3.5 s plasma-treated, c) AMP ampicillin-loaded, d) F-3.5s+AMP plasmatreated and ampicillin-loaded, e) AMP+PEG ampicillin-loaded and PEG-coated, f) F3.5s + AMP +PEG plasma-treated, ampicillin-loaded and PEG-coated PP meshes. Cells were cultured for $24 \mathrm{~h}$ and images of crystal violet staining were captured at $16 \mathrm{X}$ magnification; scale bar $=100 \mu \mathrm{m}$. Graph shows a box plot depicting the adherent cell number per unit surface (10 fields per condition). Values represent two independent experiments carried out each time in triplicates.* indicates statistically significant differences vs UT sample.

Figure 10. Summary of the effects of the different plasma treatments performed to PP fibres on the adsorption of drugs and on the cell adhesion and morphology. 


